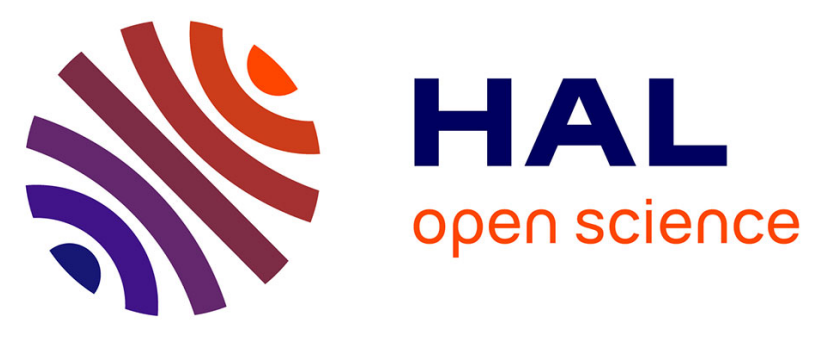

\title{
Dysfunction of mitochondrial Lon protease and identification of oxidized protein in mouse brain following exposure to MPTP: Implications for Parkinson disease
}

Anne-Laure Bulteau, Natalia P. Mena, Françoise Auchère, Irene Lee, Annick Prigent, Christian S. Lobsiger, Jean-Michel Camadro, Etienne C. Hirsch

\section{To cite this version:}

Anne-Laure Bulteau, Natalia P. Mena, Françoise Auchère, Irene Lee, Annick Prigent, et al.. Dysfunction of mitochondrial Lon protease and identification of oxidized protein in mouse brain following exposure to MPTP: Implications for Parkinson disease. Free Radical Biology and Medicine, 2017, 10.1016/j.freeradbiomed.2017.03.036 . hal-01501657

\section{HAL Id: hal-01501657 https://hal.sorbonne-universite.fr/hal-01501657}

Submitted on 4 Apr 2017

HAL is a multi-disciplinary open access archive for the deposit and dissemination of scientific research documents, whether they are published or not. The documents may come from teaching and research institutions in France or abroad, or from public or private research centers.
L'archive ouverte pluridisciplinaire HAL, est destinée au dépôt et à la diffusion de documents scientifiques de niveau recherche, publiés ou non, émanant des établissements d'enseignement et de recherche français ou étrangers, des laboratoires publics ou privés. 


\section{Dysfunction of mitochondrial Lon protease and identification of oxidized protein in mouse brain following exposure to MPTP: Implications for Parkinson disease}

Anne-Laure Bulteau ${ }^{\mathrm{a}, \mathrm{b}, \mathrm{c}}$, , Natalia P. Mena ${ }^{\mathrm{a}, \mathrm{b}, \mathrm{c}, \mathrm{d}, \mathrm{e}}$, Françoise Auchère ${ }^{\mathrm{f}}$, Irene Lee ${ }^{\mathrm{g}}$, Annick Prigent ${ }^{\text {ab, }, c}$, Christian S. Lobsiger ${ }^{\text {a,b,c }}$, Jean-Michel Camadro ${ }^{\text {f }}$, Etienne C. Hirsch ${ }^{\text {a,b, }, \text { * }}$

a INSERM, U1127, The Brain and Spinal Cord Institute (ICM), Hôpital de la Salpêtrière, 75013 Paris, France;

${ }^{\mathrm{b}}$ CNRS, UMR 7225, Centre de Recherche en neurosciences, ICM, Thérapeutique expérimentale de la neurodégénérescence, Hôpital de la Salpêtrière, Paris, F-75005 Paris, France

${ }^{\mathrm{c}}$ Sorbonne Universités, Université Pierre et Marie Curie, 75005 Paris, France.

${ }^{\mathrm{d}}$ Department of Biology, Faculty of Sciences, Universidad de Chile, Santiago, Chile

${ }^{\mathrm{e}}$ Millennium Institute of Cell Dynamics and Biotechnology, Santiago, Chile

${ }^{\mathrm{f}}$ Laboratoire Mitochondries, Métaux et Stress Oxydatif, Département de Pathologie Moléculaire et Cellulaire, Institut Jacques Monod, Université Paris-Diderot/CNRS, Paris, France

${ }^{\mathrm{g}}$ Case Western Reserve University Department of Chemistry, Cleveland, OH 44106, USA

*Address correspondence to: Etienne Hirsch, ICM, Thérapeutique expérimentale de la neurodégénérescence, Hôpital de la Salpêtrière, Paris, 75013 France.

Tel.: +331572745 57; fax: + 33157274782 .

E-mail address: etienne.hirsch@upmc.fr (E. C. Hirsch)

*or to: Anne-Laure Bulteau. Institut de Génomique Fonctionnelle de Lyon (IGFL); Ecole Normale Supérieure (ENS) de Lyon-CNRS-UMR5242 ; Lyon, France.anne-laure.bulteau @enslyon.fr. Phone: 33-04-26-73-13-42. 


\section{ABSTRACT}

Compelling evidence suggests that mitochondrial dysfunction leading to reactive oxygen species (ROS) production and protein oxidation could represent a critical event in the pathogenesis of Parkinson's disease (PD). Pioneering studies have shown that the mitochondrial matrix contains the Lon protease, which degrades oxidized, dysfunctional, and misfolded protein. Using the PD animal model of 1-methyl-4-phenyl-1, 2, 3, 6-tetrahydropyridine (MPTP) intoxication in mice, we showed that Lon protease expression increased in the ventral mesencephalon of intoxicated animals, concomitantly with the appearance of oxidized proteins and dopaminergic cell loss. In addition, we report that Lon is inactivated by ROS. Moreover, proteomic experiments provide evidence of carbonylation in $\alpha$-ketoglutarate dehydrogenase $(\mathrm{KGDH})$, aconitase or subunits of respiratory chain complexes .Lon protease inactivation upon MPTP treatment in mice raises the possibility that Lon protease dysfunction is an early event in the pathogenesis of PD.

\section{KEYWORDS}

Oxidative stress, Parkinson's disease, Lon protease, mitochondria, protein oxidation. 


\section{Introduction}

It is becoming clear that mitochondrial dysfunction plays a critical role in the pathogenesis of a number of neurodegenerative disorders, including Alzheimer's disease, Parkinson's disease (PD) and Friedreich's ataxia [1, 2]. PD is a common neurodegenerative disease whose main motor symptoms are due to the progressive loss of dopaminergic neurons in the substantia nigra pars compacta $(\mathrm{SNpc})$ [3]. The molecular mechanisms leading to neuronal degeneration remain poorly understood, but converging evidence involves mitochondrial dysfunction. Toxins such as 1-methyl-4-phenyl-1,2,3,6-tetrahydropyridine (MPTP) cause parkinsonian symptoms in humans and animals and promote dopaminergic neurons loss by impairing mitochondrial complex I, leading, among other mechanisms, to reactive oxygen species (ROS) production [4-6]. Complex I inhibition is also believed to exert its toxicity by decreasing ATP production [7]. ATP depletion in dopaminergic neurons would redistribute dopamine to the cytosol with resulting oxidative damage to mitochondrial protein [8]. In order to maintain protein homeostasis mitochondria possess a number of proteases [9]. Mammalian mitochondria contain four major ATP-dependent proteases, Lon, Clp-like i-AAA and m-AAA proteases $[10,11]$. Within the mitochondrial matrix, the ATP-dependent Lon protease has been suggested to catalyze the degradation of oxidatively modified protein [12-14]. A detailed proteomic substrate screens in yeast revealed a preference of Pim1/Lon for conformationally labile peptides and a role in preventing protein aggregation $[15,16]$. Aconitase, a Krebs cycle enzyme known to be susceptible to oxidative inactivation, has been shown to be a substrate of the Lon protease when the enzyme is inactivated upon treatment with oxygen radicals [17]. Accumulation of oxidatively modified protein in mitochondria upon aging and in a number of neurodegenerative diseases may therefore be due, at least in part, to a decreased ability of 
mitochondrial proteases, such as Lon, to clear out damaged proteins [18]. In support of this notion, a recent study demonstrated that overproduction of Lon counteracts the accumulation of oxidatively damaged proteins during aging in Podospora anserina [19]. Lon knockdown in WI38 fibroblasts leads to impaired mitochondrial function, accumulation of oxidatively modified proteins and cell death occurring via apoptosis and necrosis [20]. The regulation of Lon is currently not well studied but growing evidence suggests that Lon is modulated by stress [2123]. Clearly, the level of oxidatively modified proteins reflects the balance between free radical damage and proteolytic degradation [23]. It is therefore important to investigate the response of Lon protease in the mitochondria of mice injected with MPTP, an established model of PD. The current study was undertaken to characterize the effects of MPTP treatment on Lon protease activity and to begin to assess how alterations in Lon protease function may contribute to the development of dopaminergic neuron injury. Our results demonstrate that MPTP treatment induced a significant decline in Lon function in mouse midbrain. This was accompanied by selective carbonylation of mitochondrial key proteins such as aconitase and $\alpha$-ketoglutarate dehydrogenase $(\mathrm{KGDH})$. We also characterized the expression of Lon protease in substantia nigra (SN) from control subjects and PD patients. Taken together, these findings suggest that Lon protease may be particularly vulnerable to inactivation in conditions associated with elevated oxidative stress resulting in mitochondrial dysfunction and neuron cell death.

\section{MATERIAL AND METHODS}

\section{Chemicals and antibodies.}

MPTP hydrochloride, 6-hydroxydopamine hydrobromide, and $\mathrm{MPP}^{+}$were purchased from (Sigma, Saint-Quentin Fallavier, France). In addition, the following antibodies were used: 
mouse anti-TH (Diasorin, Hudson, WI, USA), anti-Porin (VDAC1, Abcam) and human anti-actin (Sigma, Saint-Quentin Fallavier, France). Anti-Lon protease, anti-aconitase and anti-proteasome antibodies were as previously described [24].

\section{MPTP intoxication and isolation of mitochondria.}

Male C57BL/6J mice (12 weeks old) were obtained from (Janvier Breeding Center, Le Genest-St-Isle, France). Animals were housed, handled, and cared for in accordance with the Guide for the Care and Use of Laboratory Animals (NCR [National Research Council] 1996) and European Union Council Directive 86/609/EEC, and the experimental protocols were carried out in compliance with institutional ethical committee guidelines for animal research. All efforts were made to minimize the number of animals used and their suffering. For all studies, mice were maintained on a 12:12 h light/dark cycle with lights on at $6.30 \mathrm{a} . \mathrm{m}$. The room temperature was kept at $23{ }^{\circ} \mathrm{C}$, with free access to standard diet and tap water. Mice were injected i.p. 4 times (at 2-h intervals over 1 day) with $20 \mathrm{mg} / \mathrm{kg}$ MPTP free base in saline or a corresponding volume of saline alone. At selected time points, animals were killed and the ventral mesencephali of salineinjected and MPTP-injected mice were dissected out in (210 mM mannitol, $70 \mathrm{mM}$ sucrose, 1.0 mM EDTA, 5.0 mM MOPS at pH 7.4) and homogenized with a glass/Teflon Potter homogenizer. Mitochondria were isolated by differential centrifugation, as previously described [25]. Matrix preparation was carried out as previously described [25], by hypotonic shock followed by sonication (1 min, 3 times) in $10 \mathrm{mM}$ HEPES buffer (without EDTA; pH 7.2) and centrifugation $\left(100,000 \mathrm{~g}, 60 \mathrm{~min}, 4^{\circ} \mathrm{C}\right)$. We used the Bradford protein assay to determine the protein content of isolated mitochondria, with bovine serum albumin as the standard.

\section{Immunohistochemistry}

After extraction from the skull, brains were further post-fixed overnight in fresh $4 \%$ PFA/PBS solution, and cryoprotected with $30 \%$ sucrose in PBS. Coronal free- floating striatal 
and mesencephalic sections (30- $\mu$ m thick) were prepared using a freezing microtome (Leica) and collected in 10 regularly spaced series.Immunohistochemical staining on mouse brain sections was performed as previously described [26]. The primary antibody was used: anti-TH (1:1000; Pel- Freez Biochemicals). Staining was revealed by the ABC method (Vector Laboratories) with 3,3-diaminobenzidine (DAB) as the peroxidase substrate. DAB-immunostained sections were analyzed by bright- field microscopy, using a Leitz microscope equipped with image analysis software (Mercator, ExploraNova, La Rochelle, France). TH+ cell bodies were quantified stereologically on regularly spaced sections covering the whole substantia nigra pars compacta (SNpc) using the VisioScan stereology tool.

\section{Human postmortem tissue.}

Brains were obtained postmortem from control individuals with no known history of neurological or psychiatric disorders and from patients with clinically defined PD that was histologically confirmed (nigral neuronal loss; presence of Lewy bodies in the SN and locus ceruleus). For Western blot analysis, we analyzed the specimens from 3 parkinsonian patients and 3 controls with comparable ages at death and interval between death and freezing of the brain.

\section{Tissue preparation for Western blot analysis}

Within $2 \mathrm{~h}$ after autopsy, the brains were dissected and blocks of hemibrainstem were frozen in dry ice and stored at $80{ }^{\circ} \mathrm{C}$. Serial $20-\mu \mathrm{m}$-thick sections were cut from the frozen blocks at $-12{ }^{\circ} \mathrm{C}$ using a cryostat, thaw-mounted onto gelatin/chromalum-coated glass slides, desiccated, and stored at $-80^{\circ} \mathrm{C}$. SN from PD patients and age-matched controls was collected from frozen mesencephalic brain slices. The boundaries of subregions were delineated according to Hirsch $e t$ al. [27]. Tissue (5-12 mg) was scraped with a cold plastic blade onto the glass slide, which was placed on dry ice. The collected material was transferred to an Eppendorf tube and stored at -80 ${ }^{\circ} \mathrm{C}$. For protein analyses, frozen specimens were suspended and homogenized with a glass/Teflon 
Potter homogenizer in a chilled lysis buffer in $0.6 \mathrm{M}$ sorbitol, $50 \mathrm{mM}$ Tris- $\mathrm{HCl}$, $\mathrm{pH} 7.5$ supplemented with complete protease inhibitor. Protein quantification was performed using the Bradford method.

\section{Determination of cytosolic and mitochondrial glutathione levels}

Glutathione levels were determined with a modified version of the recycling enzymatic assay, as previously described [28]. Specific glutathione content was calculated from standard curves obtained with various concentrations of oxidized disulphide glutathione (GSSG), and is expressed in nmoles of glutathione/mg of protein. The assay is based on the reduction of each GSSG molecule to give two reduced glutathione (GSH) molecules, and the reading is in GSSG equivalents because GSSG is used as the standard, so the total measured specific glutathione content is $0.5 \mathrm{GSH}+\mathrm{GSSG}$. For the quantification of oxidized glutathione (GSSG), samples (including GSSG standards) were treated with 2\% (vol/vol) 4-vinylpyridine for $1 \mathrm{~h}$ at room temperature before analysis. The cytosolic and mitochondrial GSH/GSSG ratios were calculated as follows: GSH/GSSG $=2[$ (total glutathione) $-\mathrm{GSSG}] /$ GSSG. All the data points shown in the figures and the values given are the means of at least three determinations.

\section{Detection and quantification of carbonylated proteins}

Carbonylated proteins were detected and analyzed after the derivatization of protein carbonyl groups with 2, 4-dinitrophenylhydrazine (DNPH) (Protein Oxidation Detection Kit, OxyBlot ${ }^{\mathrm{TM}}$, Millipore). Derivatized samples were incubated in Laemmli sample buffer for $5 \mathrm{~min}$ at $100{ }^{\circ} \mathrm{C}$, resolved by SDS-PAGE in a 4-20\% acrylamide gel and electrotransferred onto a Hybond nitrocellulose membrane (GE Healthcare, Piscataway, NJ, USA). The primary antibody for Western blotting was raised against dinitrophenylhydrazone, and primary antibody binding was detected with a peroxidase-conjugated secondary antibody and a chemiluminescent substrate (ECL plus Western blotting detection system, (GE Healthcare). Western blots were quantified 
using Image J. For carbonyl groups quantification on protein after MPTP treatment mitochondria lysates were prepared for analysis using the OxiSelect protein carbonyl ELISA kit, following the manufacturer's protocol (Cell Biolabs, San Diego, USA).

\section{Monitoring specific activity of Lon protease from isolated midbrain mitochondrial matrix}

Methods and materials for the synthesis of peptide substrate FRETN 89-98 and inhibitor DBN9310 are detailed in [29]. Reactions containing $50 \mathrm{mM}$ HEPES (pH 8), $5 \mathrm{mM} \mathrm{Mg}(\mathrm{OAc}) 2,2$ mM DTT, $5 \mathrm{mM}$ imidazole, and $100 \mu \mathrm{M}$ FRETN $89-98$ in the absence and presence of $1 \mathrm{mM}$ ATP were incubated at $37{ }^{\circ} \mathrm{C}$ for 1 min as previously described [29]. Five micrograms of the purified matrix from midbrain mitochondria culture were added and cleavage of peptide was observed by monitoring the fluorescent emission at $420 \mathrm{~nm}(\lambda \mathrm{ex}=320 \mathrm{~nm})$ for $1 \mathrm{~h}$ in the absence and presence of DBN9310 $\mu \mathrm{M}$, a specific inhibitor of Lon protease.

\section{Proteasomal peptidase activities}

The ventral mesencephali of saline-injected and MPTP-injected mice were dissected out in $25 \mathrm{mM}$ Tris- $\mathrm{HCl} \mathrm{pH}$ 7.5. Cytosol were collected after sonication and centrifugation (20 000 $\left.\mathrm{g}, 4^{\circ} \mathrm{C}, 20 \mathrm{~min}\right)$. Degradation of $25 \mu \mathrm{M}$ Suc-Leu-Leu-Val-Tyr-7-amido-4-methylcoumarin [chymotrypsin like activity] and $150 \mu \mathrm{M}$ N-Cbz-Leu- Leu-Glu-b7-amino-4- methylcoumarin [Caspase-like activity] was monitored for 20 min using $20 \mu \mathrm{g}$ protein by spectrofluorimetry (excitation/emission wavelengths: $350 / 440 \mathrm{~nm}$ for aminomethylcoumarin) as described in [7]. Assay for aconitase activity

Mitochondria were suspended in $25 \mathrm{mM}$ phosphate buffer $\mathrm{pH} 7.25$ supplemented with $0.05 \%$ Triton $\mathrm{X}-100$ and aconitase activity was assayed spectrophotometrically at $340 \mathrm{~nm}$, as previously described [24]. The results are expressed in $\mu$ moles of reduced NADPH $/ \mathrm{min} / \mathrm{mg}$ protein, and all data points in the figures are the means of at least three determinations. 


\section{Assay for $\mathrm{KGDH}$}

Mitochondria were diluted in $25 \mathrm{mM}$ MOPS, $0.05 \%$ Triton X-100, pH 7.4, and KGDH activity was assayed spectrophotometrically as the rate of $\mathrm{NAD}^{+}$reduction to NADH upon addition of $5 \mathrm{mM} \mathrm{MgCl} 2,2.5 \mathrm{mM} \alpha$-ketoglutarate, $0.1 \mathrm{mM}$ CoASH, $0.2 \mathrm{mM}$ thiamine pyrophosphate, and $1 \mathrm{mM} \mathrm{NAD}^{+}$, as previously described in [30]. The results are expressed in nmoles reduced $\mathrm{NADH} / \mathrm{min} / \mathrm{mg}$ protein, and all data points in the figures and the values listed are the means of at least three determinations.

\section{Complex I activity and ATP determination}

Rotenone-sensitive NADH oxidation by complex I was recorded using the ubiquinone analogue decyl-ubiquinone as electron acceptor as described in [7].

\section{Purification of carbonylated proteins}

The biotinylation of the carbonyls in mitochondria proteins followed a modified procedure described by Meany et al. [32]. Mitochondria isolated from cells or from the ventral mesencephali of saline-and MPTP-injected mice were resuspended in $100 \mathrm{mM}$ sodium acetate and $20 \mathrm{mM} \mathrm{NaCl}, \mathrm{pH} 5.5$ with $1 \%$ SDS. The lysate was then centrifuged at $13,000 \times \mathrm{g}$ and the supernantant was treated with biotin hydrazine solution (5 mM in DMSO) (Pierce, Rockford, IL, USA); the mixture was incubated at room temperature for $2 \mathrm{~h}$ while shaking. The mixture was then cooled on ice and an equal volume of $30 \mathrm{mM}$ sodium cyanoborohydride in PBS was added to stabilize the hydrazone. After dialysis against PBS, biotinylated proteins were then separated on $100 \mu \mathrm{l}$ of high-affinity streptavidin-agarose resin (Pierce) that had been washed with $50 \mathrm{mM}$ Tris- $\mathrm{HCl}$ buffer $\mathrm{pH} 7.5$ (0.6 M sorbitol). After incubation with the resin for $30 \mathrm{~min}$, the suspension was centrifuged at $750 \mathrm{~g}$ for $1 \mathrm{~min}$ to pellet the streptavidin agarose beads. 


\section{Mass spectrometry analyses: trypsic digestion and nanoLC fractionation}

The streptavidin agarose beads (with bound biotinylated proteins) were processed for mass spectrometry as follows: the beads were resuspended in $50 \mathrm{mM}$ ammonium acetate $\mathrm{pH} 7.5$ supplemented with $2 \mu \mathrm{g} / 100 \mu \mathrm{l}$ trypsin (Sigma, proteomic grade) and incubated overnight at 37 ${ }^{\circ} \mathrm{C}$. The beads were removed by centrifugation and the supernatant was concentrated for separation of the peptides by nanoLC. The samples were separated on an Ultimate 3,000 nanoLC system (Dionex, Sunnyvale, CA, USA), using a C18 column (Acclaim Pep Map 100 C18, 3 $\mu \mathrm{m}, 100 \AA, 75 \mu \mathrm{m}$ id $\times 15 \mathrm{~cm}$, Dionex) at a flow rate of $300 \mathrm{nl} / \mathrm{min}$. Buffer A was $2 \%$ acetonitrile $(\mathrm{ACN})$ in water plus $0.05 \%$ trifluoroacetic acid (TFA) and buffer $\mathrm{B}$ was $80 \% \mathrm{ACN}$ in water plus 0.04\% TFA. Peptides were desalted on the precolumn for $3 \mathrm{~min}$, in buffer A alone. They were then separated over a 60 min period on the following gradient: 0 to $20 \%$ B over $10 \mathrm{~min}, 20 \%$ to $55 \% \mathrm{~B}$ over $45 \mathrm{~min}$ and $55 \%$ to $100 \% \mathrm{~B}$ over $5 \mathrm{~min}$. Chromatograms were recorded at a wavelength of $214 \mathrm{~nm}$. Peptide fractions were collected with a Probot microfraction collector (Dionex). CHCA (LaserBioLabs, Sophia-Antipolis, France) was used as the MALDI matrix. The matrix ( $2 \mathrm{mg} / \mathrm{ml}$ in $70 \%$ ACN in water supplemented with $0.1 \%$ TFA) was continually added to the column effluent via a micro "T" mixing piece, at a flow rate of $1.2 \mu 1 / \mathrm{min}$. After a 14 -min run, a start signal was sent to the Probot to initiate fractionation. Each fraction was collected over a period of $10 \mathrm{sec}$ and spotted onto a MALDI sample plate (1,664 spots per plate, Applied Biosystems, Foster City, CA, USA).

\section{MALDI-MS and MS/MS}

MS and MS/MS analyses of off-line-spotted peptide samples were carried out on a 4800+ MALDI-TOF/TOF Analyzer (Applied Biosystems). After screening of all LC-MALDI sample positions in MS-positive reflector mode, with 1500 laser shots, the automatically selected precursors were fragmented at a collision energy of $1 \mathrm{kV}$, using air as the collision gas (pressure 
of $\sim 2 \times 10^{-6}$ Torr). MS spectra were acquired at $\mathrm{m} / \mathrm{z}$ values between 800 and 4000 . For internal calibration, we used the parent ion of Glu1-fibrinopeptide at an $\mathrm{m} / \mathrm{z} 1570.677$ diluted in the matrix ( 3 femtomoles per spot). Up to 12 of the most intense ion signals per spot position, with $\mathrm{S} / \mathrm{N}>12$, were selected as precursors for MS/MS acquisition. Peptides and proteins were identified with GPSTM Software V 3.1 (Applied Biosystems), using the Mascot algorithm. We used each MS/MS spectrum as a query against the Uniprot/Swissprot database (release 57 of January 2010, 6569 entries for Mus. musculus). Searches were carried out with various modifications of oxidized methionine and $\mathrm{N}$-ethyl-maleimide-labeled cysteine parameters enabled. The Mascot search engine was used, with a tolerance of one incorrect cleavage during trypsin digestion, a precursor ion mass accuracy of $50 \mathrm{ppm}$ and a fragment ion mass accuracy of 0.3 Da. Protein identifications were based on the acceptance of MS/MS spectra with an expectation value $<10^{-4}$, as such spectra made the greatest contribution to the overall Mascot score.

\section{Statistical analysis}

All values are expressed as the mean \pm SEM. Differences in means between 2 groups were analyzed using a 2-tailed Student's $t$ test or, when data were not normally distributed, with a nonparametric Mann-Whitney $U$ test. Differences in means among multiple data sets were analyzed using 1- or 2-way ANOVA with time, treatment, or genotype as the independent factors.

\section{RESULTS}

Oxidative modification of mitochondrial and cytosolic protein in the MPTP mouse model of $P D$ 
Mitochondrial neurotoxin MPTP reproduces several PD-linked cellular alterations, such as inhibition of mitochondrial complex I, increased production of ROS and iron accumulation in dopaminergic neurons [33]. Thus, we sought information on relative alterations in the levels of oxidized mitochondrial and cytosolic proteins due to MPTP treatment, using immunological detection of protein carbonyls. As shown in Fig. 1A, MPTP treatment (four i.p. injections of MPTP- $\mathrm{HCl}$ at $2 \mathrm{~h}$ intervals) induced a distinct increase in mitochondrial levels of oxidatively modified protein in the ventral midbrain of intoxicated mice. These levels peaked at day 4 postMPTP treatment and lasted even at day 7. Oxidative modification was not global in nature but appeared specific to distinct high molecular weight proteins, some of which exhibited a greater degree of oxidation than others. MPTP treatment induced the generation of ROS by the mitochondria, resulting in the appearance of oxidized forms of cytosolic proteins. As shown in Fig. 1B, oxidized proteins peaked at $12 \mathrm{~h}$ after MPTP treatment. Carbonyl group quantification on protein showed a 3 fold increased of mitochondrial protein oxidation at day 2 after MPTP treatment compare to saline mice Fig. 1C. We assessed the extent of nigrostriatal pathway injury by quantifying the number of $\mathrm{TH}$-positive neurons in the $\mathrm{SN}$ and the level of striatal $\mathrm{TH}$ immunoreactivity (Fig. 2A, B). MPTP injection induced a significant death of TH-positive neurons when compared to saline-injected animals. Loss of dopaminergic neurons was also visualized by a Western blot against tyrosine hydroxylase (Fig. 2C). These results showed that mitochondrial proteins were the main targets of the oxidative stress induced by MPTP treatment that compromized the maintenance of the dopaminergic nigrostriatal pathway. We then sought to identify these proteins, since this might give insight into the mechanisms by which they can affect the cellular function of dopaminergic neuron.

\section{Identification and characterization of mitochondrial oxidized proteins after MPTP treatment}

To identify the oxidized proteins that had accumulated in midbrain mitochondria by day 7 
after MPTP treatment, we applied a global proteomic approach. We developed a strategy using biotin hydrazide labeling and we purified potentially carbonylated proteins with "biotin/avidin" purification [30]. In this procedure mitochondrial fractions were prepared from mice midbrain 7 days after MPTP treatment. Proteins were first incubated with biotin hydrazine and were then purified by affinity chromatography on streptavidin-agarose beads. Proteomic analyses (Table 1) revealed that, in MPTP-treated mice, key enzymes in mitochondrial metabolism, including enzymes of the TCA cycle (aconitase and KGDH) and complexes of the mitochondrial respiratory chain were carbonylated. Membrane protein complexes I to V from the OXPHOS machinery cover $68 \%$ of the 24 carbonylated identified proteins, including $10 / 45$ complex I subunits, 2/4 complex II subunits, 1/11 complex III subunits, 4/13 complex IV subunits and 3/16 complex V subunits. The OXPHOS complexes are known to be targets of ROS [34]. However, our study has revealed new OXPHOS targets of ROS-induced carbonylation, which are detailed in Table I.

A general deficit of Fe-S cluster proteins, such as aconitase, a tricarboxylic acid cycle mitochondrial enzyme that contains a $4 \mathrm{~F}-4 \mathrm{~S}$ cluster as prosthetic group, is a phenotype classically associated with oxidative stress in the mitochondria [35]. To evaluate the effect of carbonylation due to MPTP treatment on aconitase activity, we isolated mitochondria from midbrain at day 7 post-injection and measured the activity of the enzyme. Complex I inhibition due to MPTP resulted in a time-dependent inhibition of aconitase (Fig. 3A). As KGDH and SDH have been described as oxidation targets in various biological systems and were found to be oxidatively modified in our proteomic study, we measured their activities [36, 37]. As shown in Fig. 3B, mitochondria isolated at 7 days after MPTP treatment demonstrated a 60\% inhibition of KGDH activity. These data suggest that carbonylation of KGDH can compromise Krebs cycle activity. However, no change was observed in SDH activity (data not shown). 


\section{Cellular distribution of glutathione between cytosol and mitochondria is modified in the ventral mesencephalon of MPTP intoxicated mice}

Glutathione is usually found in the cytosol and in other compartments including the endoplasmic reticulum, nucleus and mitochondria [38]. Mitochondrial and cytosolic GSH/GSSG ratios may vary independently, and changes in this ratio contribute to the response of mitochondria to redox signals and oxidative damage. However, glutathione cannot be synthesized within mitochondria and must be imported into the mitochondrial matrix from the cytosol. We measured total specific glutathione (GSH + GSSG) levels in cytosolic fractions and isolated mitochondria at day 7 after MPTP treatment (Fig. 4). In saline-injected mice, glutathione was present mostly in the cytosol, which contained $237 \pm 11.8$ nmoles total glutathione/mg protein, whereas only $35.9 \pm 7.5$ nmoles total glutathione/mg protein was found within the mitochondria (Fig. 4). The distribution of glutathione pools between the cytosol and mitochondria was very different in the ventral mesencephalon of MPTP-intoxicated mice, with $25.8 \pm 8.5$ nmoles total glutathione/mg protein in the cytosol and $121.8 \pm 23.2 \mathrm{nmoles} / \mathrm{mg}$ protein within the mitochondria. The decrease in GSH/GSSG ratio, which is known to reflect the intracellular redox status, was even more important in mitochondria, with a value of 2.1 in in MPTP-treated mice compared to the 11.3 value in the controls (Table 2). Thus, MPTP treatment induced a change in the cellular distribution of the glutathione pools, with $40 \%$ of glutathione found within the mitochondria, versus only $6 \%$ in saline-injected mice. The redistribution of glutathione pools between the cytosol and mitochondria (Fig. 4), suggests the import of glutathione into the mitochondrial matrix to prevent oxidative stress. Furthermore, it has also been shown that GSH depletion can inhibit mitochondrial complex I, leading to protein oxidation [38]. Our data suggest a distinct role of cytoplasmic versus mitochondrial GSH pool in dopaminergic cell death. 


\section{Proteasome inhibition and complex I inhibition interact on the level of protein oxidation and glutatthione depletion}

Complex I inhibition and proteasome inhibition increased ROS production (Fig. 6B and C) suggesting that oxidized proteins accumulated because of reduced proteolysis rather than increased oxidation. Thus, complex I and proteasome inhibition contribute independently to the accumulation of oxidized proteins by increasing oxidation and reducing proteolysis, respectively.

Mitochondrial Lon protease is inactivated in the ventral mesencephalon of MPTP-intoxicated mice

In order to degrade misfolded and oxidatively modified proteins, mitochondria possess a number of proteases [10]. Within the mitochondria matrix, the ATP-dependent Lon protease has been suggested to perform this vital function [39]. In order to investigate if the accumulation of oxidized proteins in the ventral mesencephalon mitochondria of MPTP-intoxicated mice was due to a diminished capacity for removal, we measured Lon protease activity using a specific peptide. To monitor specifically Lon protease activity, we isolated mitochondrial matrix and used a specific peptide reporter, FRETN89-98, which has been shown to be degraded by human Lon but not by other mitochondrial matrix proteins such as Clp [29]. As shown in Fig. 5A, an increase in fluorescence emission signal attributed to FRETN89-98 cleavage over time was detected in the presence of $1 \mathrm{mM}$ ATP. Peptide degradation reverted to background level where ATP was omitted and in the presence of DBN93, a specific inhibitor of Lon protease. These results provide 
evidence that only Lon protease activity is measured using this peptide. As shown in Fig. 5B, a decline in Lon protease activity was not seen, even at day 7 after MPTP treatment, when the accumulation of oxidized proteins was maximal within the mitochondria (Fig. 1A). We next investigated the possible regulation of Lon protease at the protein level. It has recently been shown that Lon induction and de novo synthesis during oxidative stress adaptation is protective against the accumulation of oxidative protein damage [22, 23]. Western blot analysis revealed significant (two-fold) Lon induction within 24h after MPTP treatment, and Lon levels remained elevated for at least 7 days after treatment (Fig. 5C). This increased expression of Lon 7 days after treatment was not concomitant with an increase in activity, suggesting an inactivation of the

protease. The precise mechanism by which Lon protease became inactivated in this study remains to be determined. However, the fact that Lon inhibition was reversible upon addition of $5 \mathrm{mM}$ DTT for 30 min before measuring its activity may indicates that key thiol residues may be important in this process (Fig 5A).

\section{Lon protease expression in $\mathrm{PD}$ patients}

To evaluate the participation of Lon protease in oxidized protein accumulation within mitochondria in the SNpc of PD patients, Western blot analysis was performed on protein extracts from human postmortem tissues. We found that Lon protease was significantly increased in PD subjects compared with control subjects (Fig. 6A). To assess oxidative protein damage of PD subjects, carbonylated proteins were first derivatized with dinitrophenylhydrazine, and carbonyls were detected after gel electrophoretic separation and Western blot analysis using the "OxyBlot" method. We observed an approximate 2.4-fold increase in the accumulated levels of carbonylated proteins in PD subjects compared to control samples (Fig. 6B). The increased expression of Lon protease is accompanied by an inactivation of the enzyme (Fig. 6E). Lon induction does not seem to be sufficient to cope with the increased load of modified proteins in 
the SNpc of PD patients and might be related to increased oxidative stress events within the mitochondria. 


\section{DISCUSSION}

Our results provide support for the hypothesis that free radicals generated upon MPTP treatment mediate declines in Lon protease function, thereby altering the balance between protein oxidation and degradation in the mitochondria of dopaminergic neurons of the SN. In this scenario, enhanced ROS production by mitochondria induces Lon expression to cope with this oxidative insult. However, this activation of the protease is not sufficient to degrade all the carbonylated proteins that accumulate in the mitochondria. The potential relevance of these processes to PD-related dopaminergic neurodegeneration is indicated by an increased Lon protease expression in SN of PD patients concomitant with an accumulation of oxidized proteins.

Although the relationship of oxidative stress to PD is still unknown, basal protein oxidation is high in the SN of PD patients, and the levels of reactive carbonyls are increased in PD [40]. In a previous study, using proteomic analysis by 2D electrophoresis of transgenic mice overexpressing A30P $\alpha$-synuclein, Poon et al. were able to show that 4 proteins were preferentially oxidized [41]. Because these targets were soluble matrix, we undertook a proteomic study using purified mitochondria and purification of carbonylated proteins avoid the loss of membrane proteins that occurred in a previous study. The general screening of carbonylated proteins in midbrain mitochondria at day 7 after MPTP treatment, using biotin hydrazide protein labeling, revealed the occurrence of a specific carbonylation mechanism, targeted to a few distinct proteins (Fig. 1 and Table 1). Our results also demonstrate the advantages of this strategy for the identification of hydrophobic membrane-spanning proteins such as mitochondrial complexes. We found that mainly protein OXPHOS and Krebs cycle enzymes that are largely responsible for respiration and energy metabolism were oxidized. MPTP treatment resulted in selective oxidation of aconitase, SDH, PDH and KGDH in the ventral 
midbrain of MPTP-intoxicated mice (Table 1). It has previously been shown that the loss of NADH-linked respiration correlates closely with the degree of aconitase and KGDH inactivation and that the production of NADH by $\mathrm{KGDH}$ is rate-limiting for mitochondrial respiration in dopaminergic neurons $[42,43]$. While a direct link between loss of enzyme activity and the appearance of carbonylated enzymes remains to be established, our results reveal that MPTP treatment resulted in important metabolic changes affecting key enzymes of the mitochondrial function. It has been shown that respiratory deficiency in dopaminergic neurons in mice leads to progressive neuronal degeneration and intra-neuronal inclusions due to protein oxidation [44]. Dopamine may act as a source of cellular oxidative stress and is known to undergo oxidation to cytotoxic radicals and quinones. Such oxidations can occur spontaneously or via metal- or enzyme-catalyzed mechanisms causing oxidatively modified proteins [45]. Our results further consolidate the pivotal function of protein oxidation and modification in PD neurodegeneration.

In MPTP-treated mice, we observed a severe decrease in total glutathione levels, and, in parallel, a decrease of the GSH/GSSG ratio, indicating an increase of the content of the oxidized form GSSG and a severe intracellular oxidative stress (Fig 4). The decrease in GSH/GSSG ratio, which is known to reflect the intracellular redox status, was even more important in mitochondria (Table 2). These results strongly suggest a binding of glutathione to the proteins, maybe through a glutathionylation process. This complete redistribution of glutathione pools between the cytosol and mitochondria in MPTP-intoxicated mice, lead to a dynamic flux of reduced glutathione within the mitochondria of MPTP-treated mouse midbrain in order to protect mitochondrial proteins from oxidative damage (Fig. 4). Analysis of oxidized proteins (Fig. 1A and C) reveals more carbonylated protein in the mitochondria than in the cytosol, suggesting that the accumulation of carbonylated proteins could be a signal for glutathione import into the mitochondria, to protect proteins from further oxidation of their active site. While carbonylation 
is an irreversible modification leading to loss of protein function, protein glutathionylation has been shown to be part of a reversible regulatory process of the redox state of the cells [46]. Indeed, the redox metabolic advantage of protein S-glutathionylation is the prevention of irreversible oxidation of cystein residues involved in the active site of key enzymes [47].

The Lon protease plays a critical role in the removal of oxidized protein [14]. Aconitase, a Krebs cycle enzyme known to be susceptible to oxidative inactivation, has been shown to be a substrate of the Lon protease when the enzyme is inactivated upon treatment with oxygen radicals [13]. Recent evidence indicates that Lon may be regulated by pro-oxidants in a manner consistent with the removal of oxidatively modified protein [22, 23]. We found that, in PD patients and in MPTP-treated mice, ROS were able to activate Lon expression, but the protease remained inactive (Fig. 5 and 6E). We postulate that ROS and reactive nitrogen species (RNS) generation due to complexes I, II and III inactivation [48, 49] and Fig. 4B creates a vicious circle that leads to Lon protease inactivation. It has been shown that brain mitochondrial Lon protease can be inhibited by peroxynitrite in vitro [50]. Evidence suggests that S-nitrosylation can also impair mitochondrial protein involved in mitochondria quality control, such as a ubiquitin E3 ligase, parkin, and an antiapoptotic protein, XIAP, that influences caspase-dependent neuronal cell death [51]. In addition, Lon protease expression is stress-inducible, but when the stressors exceed the capacity of the Lon protease or repress its production, mitochondria become dysfunctional, resulting in DA neuron death (Fig. 5). The mechanism by which Lon protease becomes inactivated upon MPTP treatment remains obscure but seems to involve cystein oxidation since it is reversed by incubation with DTT. Lon has been shown to be very sensitive to oxidative modifications [52]. We cannot rule out also that part of the protein is not assembled properly due to this modification. We have recently shown that a defect in Lon protease resulted in proteasome inhibition in yeast [53]. It is well known that proteasome dysfunction is a 
consequence of oxidative stress and that proteasome inhibition induces mitochondrial dysfunction [54]. Indeed, there is a close association between mitochondrial electron transport activity and the regulatory caps of the $26 \mathrm{~S}$ proteasome, which are ATPases. The potential role of the ubiquitin-proteasome system (UPS) has been confirmed many times over and is supported by microarray and transcriptional studies on laser-capture microdissected nigral dopaminergic neurons from PD patients [55]. This creates a complex picture, in which several pathways are interconnected, especially in PD (Fig. 7). We have previously shown that proteasome inhibition increases neuronal vulnerability to normally subtoxic levels of free radicals and amplifies energy depletion following complex I inhibition [7]. The dual role of Lon may be critical for protein maintenance and mitochondrial protein degradation to prevent impairment of the $20 \mathrm{~S}$ proteasome. This observation highlights the interdependency between cytosolic and mitochondrial repair systems.

\section{CONCLUSION}

The current study indicates that Lon protease inhibition may be a primary source of oxidative stress-induced toxicity during PD. Consequently, these data suggest that pharmacologic interventions designed to preserve Lon protease activity may be beneficial in attenuating neuron death in conditions associated with oxidative stress, and may thus represent a new neuroprotective strategy in PD. Future studies must identify sites and forms of oxidative modification of Lon protease in order to fully characterize specific mechanisms by which the Lon protease is inactivated.

\section{ACKNOWLEDGMENTS}


This work was funded by the ANR contract 09-MNPS-019-0, ParkIron; the research leading to these results has received funding from the program "Investissements d'avenir" ANR10-IAIHU-06.

\section{LIST OF ABBREVIATIONS}

DAB, diaminobenzidine; DTT, dithiothreitol; DNPH, 2, 4-dinitrophenylhydrazine; GSH, reduced glutathione; GSSG, oxidized disulfide glutathione; KGDH, $\alpha$-ketoglutarate dehydrogenase; MPTP, 1-methyl-4-phenyl-1, 2, 3, 6-tetrahydropyridine; PD, Parkinson's disease; ROS, reactive oxygen species; SDH, succinate dehydrogenase; SNPC, substantia nigra pars compacta. 


\section{FIGURE LEGENDS}

Fig. 1. Detection of oxidatively modified proteins in MPTP-injected mice. Panel A. Mitochondrial extracts were prepared from ventral midbrain of saline- (S) and MPTP-injected mice at different times after treatment. To detect oxidatively modified proteins, the extracts $(5 \mu \mathrm{g}$ of protein per lane) were treated with 2, 4-dinitrophenylhydrazine to derivatize protein carbonyls and then evaluated by SDS-PAGE using polyclonal antibodies to 2, 4-dinitrophenyl moiety. Quantification of total carbonyl group was done using Image J. Panel B. Detection of carbonylated proteins in cytosolic fractions from ventral midbrain of saline- (S) and MPTPinjected mice at different times after treatment. Panel C. Total carbonyls groups on protein were measured using a ELISA method as described in Materials and Methods section. Cytosolic and mitochondrial extracts were prepared at day 2 after MPTP treatment. Total levels of carbonylation of protein of saline mice are shown in white and MPTP mice are shown in black. All data points in the pannel are the means of $n=3$ mice, and were normalized with respect to the protein content of the samples. **p $<0.01$ compared with saline-injected mice.

Fig. 2. MPTP-induced dopaminergic cell loss in mice. Panel A. Peroxidase/DAB immunohistochemistry for $\mathrm{TH}$ on coronal mesencephalic sections from saline-injected and

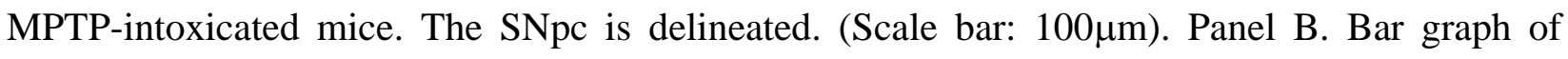
stereological counts of TH-positive cells in the SNpc of saline- and MPTP-injected mice (7 days after MPTP intoxication). **p <0.01 compared with saline-injected mice. Panel C. Loss of dopaminergic neurons at day 7 after saline or MPTP treatment was evaluated by Western blot 
using a mouse anti-tyrosine hydroxylase antibody.

Fig. 3. Effect of carbonylation on activity of key metabolic enzymes in the mesencephalon of MPTP-injected mice. Panel A. Time course of aconitase activity changes after MPTP treatment. Mitochondria were isolated from midbrain of saline- (S) and MPTP-injected mice. At different times post-MPTP injection, enzyme activities were determined as described in the Material and methods. White bar: saline-injected mice at day 7. Black bars: MPTP-injected mice. Panel B. Time course of $\alpha$-ketoglutarate dehydrogenase (KGDH) activity changes after MPTP treatment. White bar: saline-injected mice at day 7. Black bars: MPTP-injected mice. All data points in the figure are the means of at least three determinations of $n=7$ mice, and were normalized with respect to the protein content of the samples. ${ }^{*} p<0.05$ compared with saline-injected -mice; **p $<0.01$ compared with saline-injected mice.

Fig. 4. Interactions between complex I and proteasome inhibition on ROS production and glutathione depletion, and their relevance for synergistic toxicity.

Panel A. Cellular distribution of glutathione in midbrain of treated mice at day 7 post-MPTP. Total cytosolic levels of glutathione (GSH +GSSG) are shown in grey and oxidized glutathione disulfide (GSSG) levels are shown in black. All data points in the figure are the means of at least three determinations, normalized with respect to the protein content of the samples, and Student's $t$ test was used to identify significant differences $\left({ }^{*} p<0.05\right.$ and ${ }^{* *} p<0.01$ versus saline-injected mice). In our experimental conditions, mitochondrial proteins accounted for $8 \%$ of cellular proteins and cytosolic proteins accounted for $92 \%$ of cellular proteins. Panel B. Loss of complex I activity at day 7 after saline or MPTP treatment was evaluated by spectrophotometry. White bar: saline-injected mice at day 7. Black bars: MPTP-injected mice. All data points in the figure 
are the means of at least three determinations of $n=7$ mice. Panel C. Loss of proteasome activities at day 7 after saline or MPTP treatment was evaluated by spectrophotometry. White bar: salineinjected mice at day 7. Black bars: MPTP-injected miceChymotrypsin-like, peptidylglutamylpeptide hydrolase, and caspase-like activities of proteasome present in the cytoplasmic milieu were evaluated utilizing the fluorogenic peptides LLVY-MCA, LLE- MCA, respectively. The specific inhibitor MG-132 (20 $\mu \mathrm{M})$ was utilized to ensure that measured activities were due to the proteasome.

Fig. 5. Lon protease inactivation in ventral mecencephalon of MPTP-injected mice. Panel A. Monitoring of ATP-dependent peptide cleavage of FRETN 89-98 by mitochondria isolated from ventral mesencephalon of saline-injected mice. Cleavage of $100 \mu \mathrm{M}$ of FRETN by $5 \mu \mathrm{g}$ of purified matrix was monitored in the absence (white circles) and presence (black circles) of 1 mM ATP. The addition of $10 \mu \mathrm{M}$ DBN93 (white squares), which is a specific inhibitor of Lon, inhibited ATP-dependent peptidase activity, reducing it to intrinsic levels. Supplementation of mitochondrial matrix of MPTP treated mice at day 2 after treatment with $5 \mathrm{mM}$ of DTT for 30 min before enzymatic activity (black squares). Panel B. Monitoring of Lon protease activity. Mitochondria were isolated from midbrain of saline-injected (S) and MPTP-injected mice and matrices were prepared. At different times post-MPTP injection, enzyme activities were determined using $5 \mu \mathrm{g}$ of purified matrix and $100 \mu \mathrm{M}$ of FRETN 89-98 in the presence of $1 \mathrm{mM}$ ATP. White bars: saline-injected mice at day 7. Black bars: MPTP-treated mice. All data points in the figure are the means of $n=7$ mice determinations and were normalized with respect to the protein content of the samples. Panel C. Lon protease expression in the mesencephalon of MPTP- 
injected mice. Western blot analysis of Lon protease expression in ventral mesencephalon homogenates of saline- (S at day 7) and MPTP-injected mice at different time post treatment.

Fig. 6. Lon protease expression in human mesencephalon. Panel A. Immunoblots using extract of SNpc from controls (C) and PD patients (P). Panel B. Bar charts quantify Lon levels normalized by actin. ${ }^{* *} p<0.01$ versus controls. Panel C. Levels of protein carbonyls in SNpc of controls (C) and PD patients $(\mathrm{P})$. To detect oxidatively modified proteins, the extracts $(5 \mu \mathrm{g}$ of protein per lane) were treated with 2, 4-dinitrophenylhydrazine to derivatize protein carbonyls and then evaluated by SDS-PAGE using polyclonal antibodies to 2, 4-dinitrophenyl moiety. Panel D. Bar charts show relative quantification of carbonyl levels of 3 controls versus 3 PD patients. ${ }^{* *} p<$ 0.01 versus controls. Panel E. Monitoring of Lon protease activity human mesencephalon. Enzyme activities were determined using $5 \mu \mathrm{g}$ of extract of SNpc from controls (C) and PD patients $(\mathrm{P})$ and $100 \mu \mathrm{M}$ of FRETN 89-98 in the presence of $1 \mathrm{mM}$ ATP.

Fig. 7. Schematic representation of the cellular mechanisms associated with Lon protease inactivation in dopaminergic neurons after MPTP treatment. Complex I inhibition by MPTP leads to primary ROS production and mitochondrial respiratory chain complex protein deficits and inactivation due to carbonylation (carbonylated proteins specifically targeted are in red). The defective electron transport chain leads to more ROS production, increase of oxidized proteins, decreased proteasome activity and inactivation of Krebs cycle enzyme. Accordingly, inhibition of Lon protease leads to a mitochondrial stress response (activation of glutathione peroxidase [Gpx] and inhibition of glyoxalase) and to accumulation of damaged proteins in the mitochondrial matrix. M, matrix; IM, inner mitochondrial membrane; IMS, intermembrane space, OM, outer 
membrane).

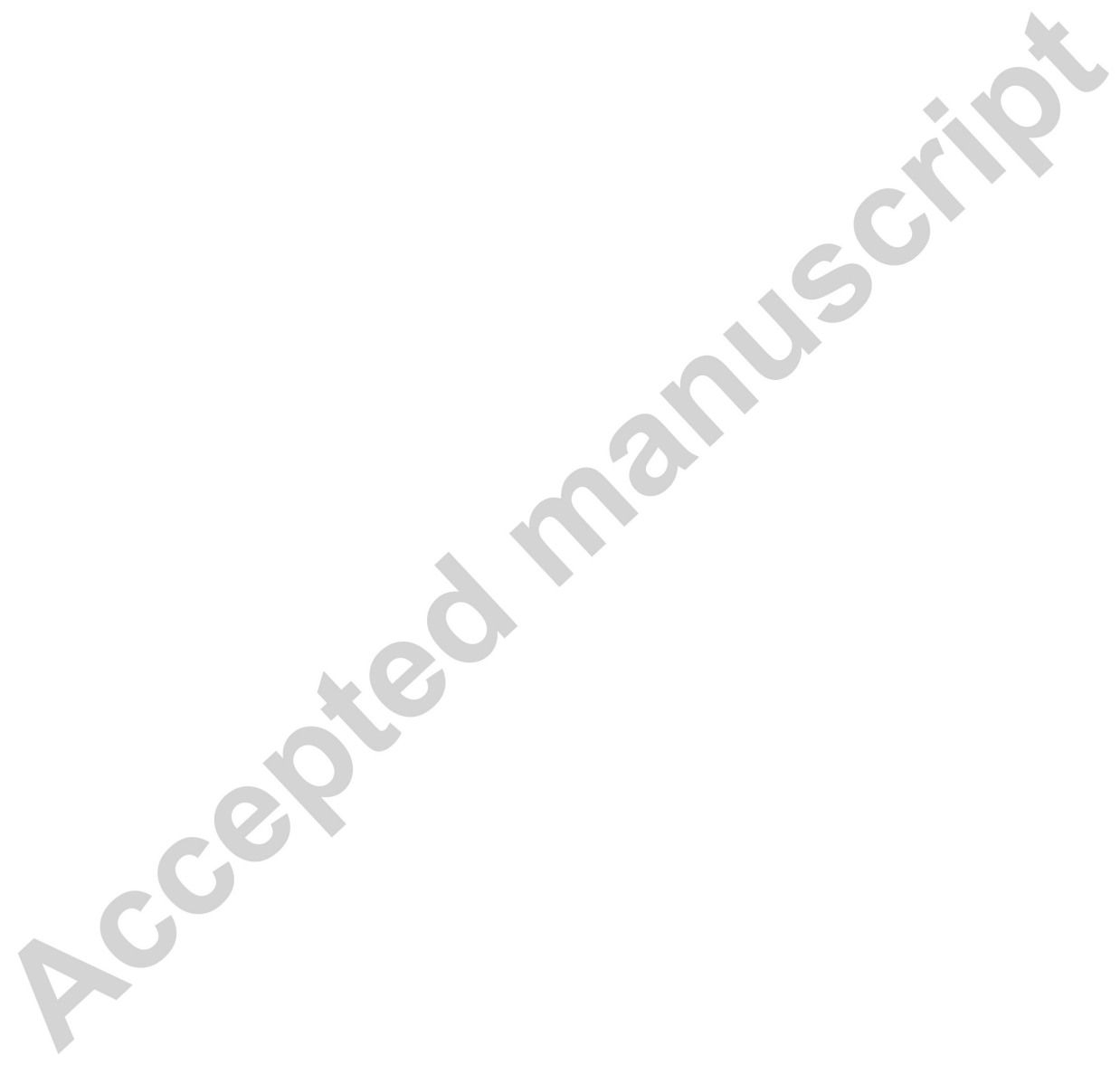




\section{REFERENCES}

[1] R. Chatuverdi, M. Flint Beal Mitochondrial diseases of the brain, Free Radic Biol Med, 63(2013) 1-29.

[2] H. Fukui, C.T. Moraes, The mitochondrial impairment, oxidative stress and neurodegeneration connection: reality or just an attractive hypothesis?, Trends Neurosci, 31 (2008) 251-256.

[3] J.A. Obeso, M. Rodriguez-Oroz, C. Marin, F. Alonso, I. Zamarbide, J.L. Lanciego, M. Rodriguez-Diaz, The origin of motor fluctuations in Parkinson's disease: importance of dopaminergic innervation and basal ganglia circuits, Neurology, 62 (2004) S17-30.

[4] J.R. Cannon, J.T. Greenamyre, Neurotoxic in vivo models of Parkinson's disease recent advances, Prog Brain Res, 184 (2010) 17-33.

[5] E.C. Hirsch, G. Hoglinger, E. Rousselet, T. Breidert, K. Parain, J. Feger, M. Ruberg, A. Prigent, C. Cohen-Salmon, J.M. Launay, Animal models of Parkinson's disease in rodents induced by toxins: an update, J Neural Transm Suppl, (2003) 89-100.

[6] T.N. Martinez, J.T. Greenamyre, Toxin models of mitochondrial dysfunction in Parkinson's disease, Antioxid Redox Signal, 16(2012) 920-934.

[7] G.U. Hoglinger, G. Carrard, P.P. Michel, F. Medja, A. Lombes, M. Ruberg, B. Friguet, E.C. Hirsch, Dysfunction of mitochondrial complex I and the proteasome: interactions between two biochemical deficits in a cellular model of Parkinson's disease, J Neurochem, 86 (2003) 12971307.

[8] M. Reale, M. Pesce, M. Priyadarshini, M.A. Kamal, A. Patruno, Mitochondria as an easy target to oxidative stress events in Parkinson's disease, CNS Neurol Disord Drug Targets, 11 (2012) 430-438. 
[9] E.I. Rugarli, T. Langer, Mitochondrial quality control: a matter of life and death for neurons, Embo J, 31 (2012) 1336-1349.

[10] W. Voos, L.A. Ward, K.N. Truscott, The Role of AAA+ Proteases in Mitochondrial Protein Biogenesis, Homeostasis and Activity Control, Subcell Biochem, 66 (2013) 223-263.

[11] S. Venkatesh, J. Lee, K. Singh, I. Lee, C.K. Suzuki, Multitasking in the mitochondrion by the ATP-dependent Lon protease, Biochim Biophys Acta, 1823 (2012) 56-66.

[12] A. Bayot, M. Gareil, A. Rogowska-Wrzesinska, P. Roepstorff, B. Friguet, A.L. Bulteau, Identification of Novel Oxidized Protein Substrates and Physiological Partners of the Mitochondrial ATP-Dependent Lon-Like Protease Pim1, J Biol Chem, 285(2010) 11445-57. [13] D.A. Bota, K.J. Davies, Lon protease preferentially degrades oxidized mitochondrial aconitase by an ATP-stimulated mechanism, Nat Cell Biol, 4 (2002) 674-680.

[14] T. Bender, C. Leidhold, T. Ruppert, S. Franken, W. Voos, The role of protein quality control in mitochondrial protein homeostasis under oxidative stress, Proteomics, 10 (2010) 1426-1443. [15] T. Major, B. von Janowsky, T. Ruppert, A. Mogk, W. Voos, Proteomic analysis of mitochondrial protein turnover: identification of novel substrate proteins of the matrix protease pim1, Mol Cell Biol, 26 (2006) 762-776.

[16] T. Bender, I. Lewrenz, S. Franken, C. Baitzel, W. Voos, Mitochondrial enzymes are protected from stress-induced aggregation by mitochondrial chaperones and the Pim1/LON protease, Mol Biol Cell, 22 (2011) 541-554.

[17] D.A. Bota, H. Van Remmen, K.J. Davies, Modulation of Lon protease activity and aconitase turnover during aging and oxidative stress, FEBS Lett, 532 (2002) 103-106.

[18] Z. Radak, Z. Zhao, S. Goto, E. Koltai, Age-associated neurodegeneration and oxidative damage to lipids, proteins and DNA, Mol Aspects Med, 32 (2011) 305-315. 
[19] K. Luce, H.D. Osiewacz, Increasing organismal healthspan by enhancing mitochondrial protein quality control, Nat Cell Biol, 11 (2009) 852-858.

[20] D.A. Bota, J.K. Ngo, K.J. Davies, Downregulation of the human Lon protease impairs mitochondrial structure and function and causes cell death, Free Radic Biol Med, 38 (2005) 665677.

[21] O. Hori, F. Ichinoda, T. Tamatani, A. Yamaguchi, N. Sato, K. Ozawa, Y. Kitao, M. Miyazaki, H.P. Harding, D. Ron, M. Tohyama, M.S. D, S. Ogawa, Transmission of cell stress from endoplasmic reticulum to mitochondria: enhanced expression of Lon protease, J Cell Biol, 157 (2002) 1151-1160.

[22] J.K. Ngo, K.J. Davies, Mitochondrial Lon protease is a human stress protein, Free Radic Biol Med, 46 (2009) 1042-1048.

[23] J.K. Ngo, L.C. Pomatto, D.A. Bota, A.L. Koop, K.J. Davies, Impairment of Lon-Induced Protection Against the Accumulation of Oxidized Proteins in Senescent Wi-38 Fibroblasts, J Gerontol A Biol Sci Med Sci, 66(2011)1178-85.

[24] A.L. Bulteau, K.C. Lundberg, M. Ikeda-Saito, G. Isaya, L.I. Szweda, Reversible redoxdependent modulation of mitochondrial aconitase and proteolytic activity during in vivo cardiac ischemia/reperfusion, Proc Natl Acad Sci U S A, 102 (2005) 5987-5991.

[25] A.L. Bulteau, A. Dancis, M. Gareil, J.J. Montagne, J.M. Camadro, E. Lesuisse, Oxidative stress and protease dysfunction in the yeast model of Friedreich ataxia, Free Radic Biol Med, 42 (2007) 1561-1570.

[26] J. Salazar, N. Mena, S. Hunot, A. Prigent, D. Alvarez-Fischer, M. Arredondo, C. Duyckaerts, V. Sazdovitch, L. Zhao, L.M. Garrick, M.T. Nunez, M.D. Garrick, R. RaismanVozari, E.C. Hirsch, Divalent metal transporter 1 (DMT1) contributes to neurodegeneration in animal models of Parkinson's disease, Proc Natl Acad Sci U S A, 105 (2008) 18578-18583. 
[27] E. Hirsch, A.M. Graybiel, Y.A. Agid, Melanized dopaminergic neurons are differentially susceptible to degeneration in Parkinson's disease, Nature, 334 (1988) 345-348.

[28] F. Auchere, R. Santos, S. Planamente, E. Lesuisse, J.M. Camadro, Glutathione-dependent redox status of frataxin-deficient cells in a yeast model of Friedreich's ataxia, Hum Mol Genet, 17 (2008) 2790-2802.

[29] J. Fishovitz, M. Li, H. Frase, J. Hudak, S. Craig, K. Ko, A.J. Berdis, C.K. Suzuki, I. Lee, Active-site-directed chemical tools for profiling mitochondrial Lon protease, ACS Chem Biol, 6 (2011) 781-788.

[30] A.L. Bulteau, S. Planamente, L. Jornea, A. Dur, E. Lesuisse, J.M. Camadro, F. Auchere, Changes in mitochondrial glutathione levels and protein thiol oxidation in yfh1 yeast cells and the lymphoblasts of patients with Friedreich's ataxia, Biochim Biophys Acta, 1822 (2012) 212225.

[31] P. Munujos, J. Coll-Canti, F. Gonzalez-Sastre, F.J. Gella, Assay of succinate dehydrogenase activity by a colorimetric-continuous method using iodonitrotetrazolium chloride as electron acceptor, Anal Biochem, 212 (1993) 506-509.

[32] D.L. Meany, H. Xie, L.V. Thompson, E.A. Arriaga, T.J. Griffin, Identification of carbonylated proteins from enriched rat skeletal muscle mitochondria using affinity chromatography-stable isotope labeling and tandem mass spectrometry, Proteomics, 7 (2007) 1150-1163.

[33] C. Perier, J. Bove, M. Vila, Mitochondria and programmed cell death in Parkinson's disease: apoptosis and beyond, Antioxid Redox Signal, 16 (2012) 883-895.

[34] P.M. Keeney, J. Xie, R.A. Capaldi, J.P. Bennett, Jr., Parkinson's disease brain mitochondrial complex I has oxidatively damaged subunits and is functionally impaired and misassembled, $\mathbf{J}$ Neurosci, 26 (2006) 5256-5264. 
[35] A.L. Bulteau, M. Ikeda-Saito, L.I. Szweda, Redox-dependent modulation of aconitase activity in intact mitochondria, Biochemistry, 42 (2003) 14846-14855.

[36] V. Adam-Vizi, Production of reactive oxygen species in brain mitochondria: contribution by electron transport chain and non-electron transport chain sources, Antioxid Redox Signal, 7 (2005) 1140-1149.

[37] L. Tretter, V. Adam-Vizi, Alpha-ketoglutarate dehydrogenase: a target and generator of oxidative stress, Philos Trans R Soc Lond B Biol Sci, 360 (2005) 2335-2345.

[38] M. Smeyne, R.J. Smeyne, Glutathione metabolism and Parkinson disease, Free Radic Biol 62(2013) 13-25.

[39] I. Lee, C.K. Suzuki, Functional mechanics of the ATP-dependent Lon protease- lessons from endogenous protein and synthetic peptide substrates, Biochim Biophys Acta, 1784 (2008) 727735.

[40] Z.I. Alam, S.E. Daniel, A.J. Lees, D.C. Marsden, P. Jenner, B. Halliwell, A generalised increase in protein carbonyls in the brain in Parkinson's but not incidental Lewy body disease, $\mathbf{J}$ Neurochem, 69 (1997) 1326-1329.

[41] H.F. Poon, M. Frasier, N. Shreve, V. Calabrese, B. Wolozin, D.A. Butterfield, Mitochondrial associated metabolic proteins are selectively oxidized in A30P alpha-synuclein transgenic mice-a model of familial Parkinson's disease, Neurobiol Dis, 18 (2005) 492-498.

[42] M.J. Kumar, D.G. Nicholls, J.K. Andersen, Oxidative alpha-ketoglutarate dehydrogenase inhibition via subtle elevations in monoamine oxidase B levels results in loss of spare respiratory capacity: implications for Parkinson's disease, J Biol Chem, 278 (2003) 46432-46439.

[43] J.K. Mallajosyula, S.J. Chinta, S. Rajagopalan, D.G. Nicholls, J.K. Andersen, Metabolic control analysis in a cellular model of elevated MAO-B: relevance to Parkinson's disease, Neurotox Res, 16 (2009) 186-193. 
[44] M.I. Ekstrand, M. Terzioglu, D. Galter, S. Zhu, C. Hofstetter, E. Lindqvist, S. Thams, A. Bergstrand, F.S. Hansson, A. Trifunovic, B. Hoffer, S. Cullheim, A.H. Mohammed, L. Olson, N.G. Larsson, Progressive parkinsonism in mice with respiratory-chain-deficient dopamine neurons, Proc Natl Acad Sci U S A, 104 (2007) 1325-1330.

[45] D.G. Anderson, S.V. Mariappan, G.R. Buettner, J.A. Doorn, Oxidation of 3,4dihydroxyphenylacetaldehyde, a toxic dopaminergic metabolite, to a semiquinone radical and an ortho-quinone, J Biol Chem, 286 (2011) 26978-26986.

[46] J.J. Mieyal, M.M. Gallogly, S. Qanungo, E.A. Sabens, M.D. Shelton, Molecular mechanisms and clinical implications of reversible protein S-glutathionylation, Antioxid Redox Signal, 10 (2008) 1941-1988.

[47] W.M. Johnson, A.L. Wilson-Delfosse, J.J. Mieyal, Dysregulation of glutathione homeostasis in neurodegenerative diseases, Nutrients, 4 (2012) 1399-1440.

[48] S. Hunot, F. Boissiere, B. Faucheux, B. Brugg, A. Mouatt-Prigent, Y. Agid, E.C. Hirsch, Nitric oxide synthase and neuronal vulnerability in Parkinson's disease, Neuroscience, 72 (1996) $355-363$.

[49] T. Obata, Y. Yamanaka, H. Kinemuchi, L. Oreland, Release of dopamine by perfusion with 1-methyl-4-phenylpyridinium ion $(\mathrm{MPP}(+))$ into the striatum is associated with hydroxyl free radical generation, Brain Res, 906 (2001) 170-175.

[50] L. Stanyer, W. Jorgensen, O. Hori, J.B. Clark, S.J. Heales, Inactivation of brain mitochondrial Lon protease by peroxynitrite precedes electron transport chain dysfunction, Neurochem Int, 53 (2008) 95-101.

[51] M.W. Akhtar, C.R. Sunico, T. Nakamura, S.A. Lipton, Redox Regulation of Protein Function via Cysteine S-Nitrosylation and Its Relevance to Neurodegenerative Diseases, Int J Cell Biol, 463756. (2012) 1-9. 
[52] B. Lu, S. Yadav, P.G. Shah, T. Liu, B. Tian, S. Pukszta, N. Villaluna, E. Kutejova, C.S.

Newlon, J.H. Santos, C.K. Suzuki, Roles for the human ATP-dependent Lon protease in mitochondrial DNA maintenance, J Biol Chem, 282 (2007) 17363-17374.

[53] N. Erjavec, A. Bayot, M. Gareil, N. Camougrand, T. Nystrom, B. Friguet, A.L. Bulteau, Deletion of the mitochondrial Pim1/Lon protease in yeast results in accelerated aging and impairment of the proteasome, Free Radic Biol Med, 56 (2013) 9-16.

[54] P.G. Sullivan, N.B. Dragicevic, J.H. Deng, Y. Bai, E. Dimayuga, Q. Ding, Q. Chen, A.J. Bruce-Keller, J.N. Keller, Proteasome inhibition alters neural mitochondrial homeostasis and mitochondria turnover, J Biol Chem, 279 (2004) 20699-20707.

[55] M. Elstner, C.M. Morris, K. Heim, A. Bender, D. Mehta, E. Jaros, T. Klopstock, T.

Meitinger, D.M. Turnbull, H. Prokisch, Expression analysis of dopaminergic neurons in Parkinson's disease and aging links transcriptional dysregulation of energy metabolism to cell death, Acta Neuropathol, 122 (2011) 75-86.

\section{Table 1}

Identified carbonyl modified mitochondrial proteins from ventral midbrain at day 7 MPTPtreatment.

\begin{tabular}{|c|c|c|c|c|}
\hline Identified proteins ${ }^{a}$ & Genes $^{b}$ & Accession numbers ${ }^{\mathrm{c}}$ & $\begin{array}{l}\text { Mascott } \\
\text { Scores }\end{array}$ & $\begin{array}{c}\text { No. of } \\
\text { sequenced } \\
\text { peptides }\end{array}$ \\
\hline ATP synthase subunit beta & Atp5b & ATPB_MOUSE & 917 & 13 \\
\hline ATP synthase subunit alpha & Atp5a1 & ATPA_MOUSE & 412 & 7 \\
\hline ATP synthase subunit coupling factor 6 & Atp5J & ADT1_MOUSE & 134 & 2 \\
\hline Aconitate hydratase, mitochondrial & Aco2 & ACON_MOUSE & 467 & 9 \\
\hline Succinate dehydrogenase flavoprotein & Sdha & DHSA_MOUSE & 339 & 4 \\
\hline Succinate dehydrogenase flavoprotein iron sulfur protein & Sdhb & DHSB_MOUSE & 74 & 1 \\
\hline Cytochrome c1 & Cyc1 & CY1_MOUSE & 280 & 6 \\
\hline 2-oxoglutarate dehydrogenase E1 complex & Ogdh & ODO1_MOUSE & 257 & 2 \\
\hline Pyruvate dehydrogenase E1 & Pdhb & ODPB_MOUSE & 103 & 1 \\
\hline
\end{tabular}


NADH dehydrogenase NDUS2 iron sulfur protein

NADH dehydrogenase NDUS5 iron sulfur protein

NADH dehydrogenase NDUS6 iron sulfur protein

NADH dehydrogenase NDUAC

NADH dehydrogenase flavoprotein 2

NADH dehydrogenase beta NDUB8

NADH dehydrogenase beta NDUB4

NADH dehydrogenase beta NDUS7

NADH dehydrogenase beta NDUB6

NADH dehydrogenase beta NDSU1

Malate dehydrogenase

Cytochrome $\mathrm{C}$ oxidase COX5a

Cytochrome $\mathrm{C}$ oxidase $6 \mathrm{~A}$

Cytochrome $\mathrm{C}$ oxidase subunit 4

Cytochrome $\mathrm{C}$ oxidase subunit 3

\begin{tabular}{clcc} 
Ndufs2 & NDUS2_MOUSE & 237 & 2 \\
Ndufs5 & NDUS5_MOUSE & 138 & 2 \\
Ndufs6 & NDUS6_MOUSE & 92 & 2 \\
Ndufa12 & NDUAC_MOUSE & 166 & 2 \\
Ndufv2 & NDUV2_MOUSE & 164 & 2 \\
Ndufb & NDUB8_MOUSE & 141 & 3 \\
Ndufb4 & NDUB4_MOUSE & 137 & 1 \\
Ndufs7 & NDUS7_MOUSE & 107 & 2 \\
Ndufb6 & NDUB6_MOUSE & 105 & 2 \\
Ndufs1 & NDUS1_MOUSE & 78 & 1 \\
Mdh2 & MDHM_MOUSE & 203 & 3 \\
Cox5a & COX5A_MOUSE & 129 & 4 \\
Cox6a1 & CX6A1_MOUSE & 120 & 2 \\
Cox4i1 & COX41_MOUSE & 110 & 2 \\
Mtco3 & COX3_MOUSE & 107 & 1 \\
\hline
\end{tabular}

${ }^{\text {a }}$ Proteins identified by MS and MS/MS (see more details in Materials and methods)

${ }^{\text {b }}$ Genes correspond to gene names found in (Mus musculus Genome Database)

${ }^{\mathbf{c}}$ Swiss prot protein database accession numbers

d Mascott scores obtained for protein identification using combined MS and MS/MS peak lists (see more details in Experimental procedures and Supplemental proteomic data). Only the proteins with Mascott Scores $\geq 37$ were considered

${ }^{\mathbf{e}}$ Number of sequenced peptides

Table 2: Mitochondria from MPTP treatd mice at day 7 are submitted to severe mitochondrial glutathione-dependent oxidative stress.

Cytosolic fractions and mitochondria were purified as described under the experimental section and the mitochondrial GSH/GSSG ratios were calculated using the following equation: $\mathrm{GSH} / \mathrm{GSSG}=2[($ total glutathione $)-$ GSSG $] /$ GSSG. All values listed are means of at least three determinations, and Student's t test was used to identify significant differences $\left({ }^{* *} \mathrm{p}<0.001\right.$ and * $\mathrm{p}<0.05$ respectively compared to saline mice).

\begin{tabular}{|l|c|c|c|c|}
\hline & \multicolumn{3}{|c|}{} \\
\hline & $\begin{array}{c}\text { Saline } \\
\text { cytosolic } \\
(\mathrm{n}=3)\end{array}$ & $\begin{array}{c}\text { Saline } \\
\text { mitochondrial } \\
(\mathrm{n}=3)\end{array}$ & $\begin{array}{c}\text { MPTP } \\
\text { cytosolic } \\
(\mathrm{n}=3)\end{array}$ & $\begin{array}{c}\text { MPTP } \\
\text { mitochondrial } \\
(\mathrm{n}=3)\end{array}$ \\
\hline & & & & \\
\hline
\end{tabular}




\begin{tabular}{|c|c|c|c|c|}
\hline $\begin{array}{c}\text { Total glutathione } \\
\text { (nmoles glutathione/mg } \\
\text { protein) }\end{array}$ & $\begin{array}{c}237 \pm \\
11.8\end{array}$ & $35.9 \pm 7.5$ & $* * 25.8 \pm 8.5$ & $* 121.8 \pm 23$ \\
\hline GSH / GSSG & 19.1 & 11.3 & 4.8 & 2.1 \\
\hline
\end{tabular}

\section{Highlights}

- Mitochondrial Lon protease is inactivated in mice model of Parkinson disease

- Lon protease is inactivated in mitochondria from substantia nigra pars compacta of PD's patients

- Defect in mitochondrial Lon protease results in oxidized proteins accumulation - OXPHOS chain complex I/IV are carbonylated in mice model of Parkinson disease

- Aconitase and KGDH are carbonylated in mice model of Parkinson disease 


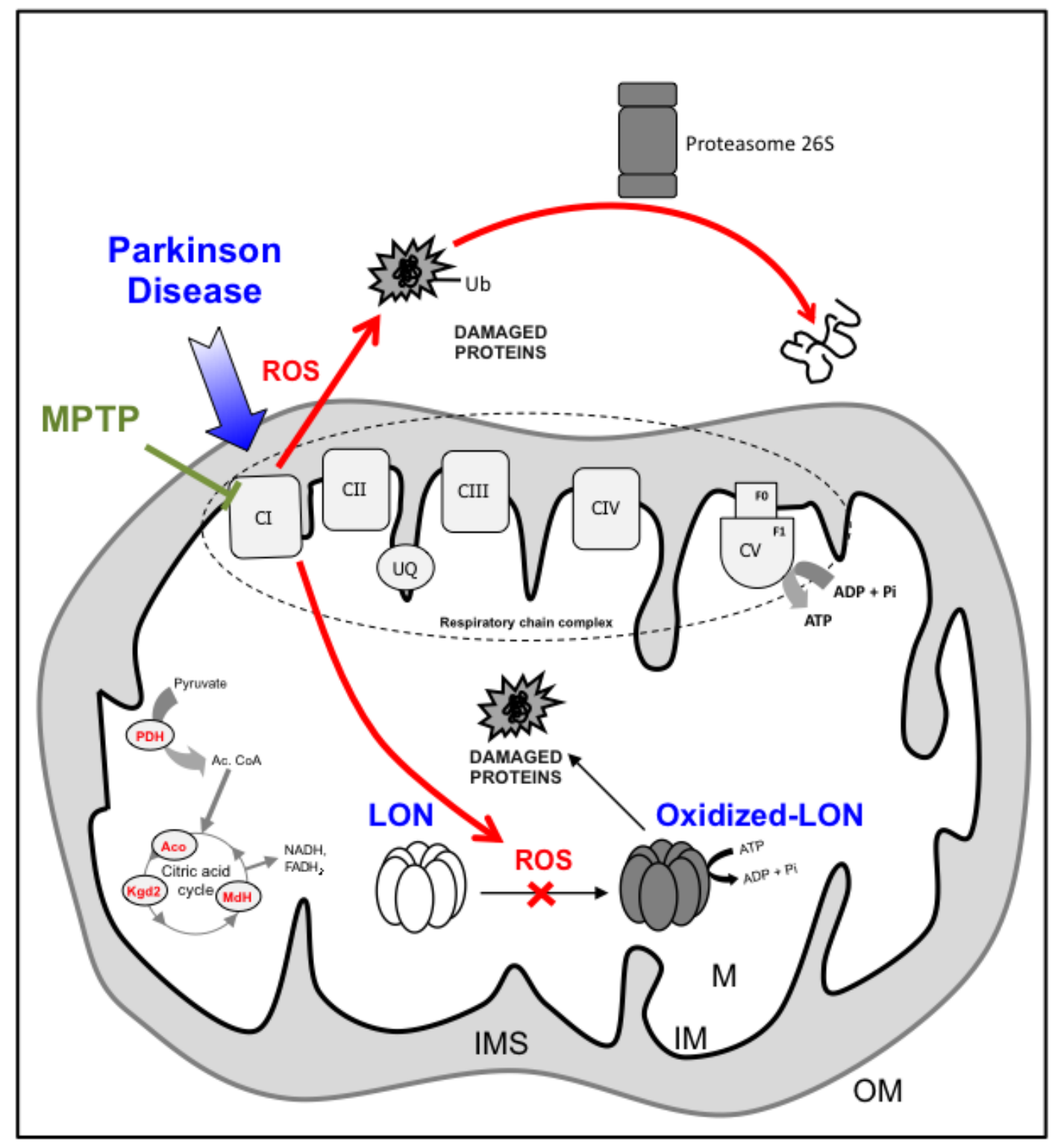



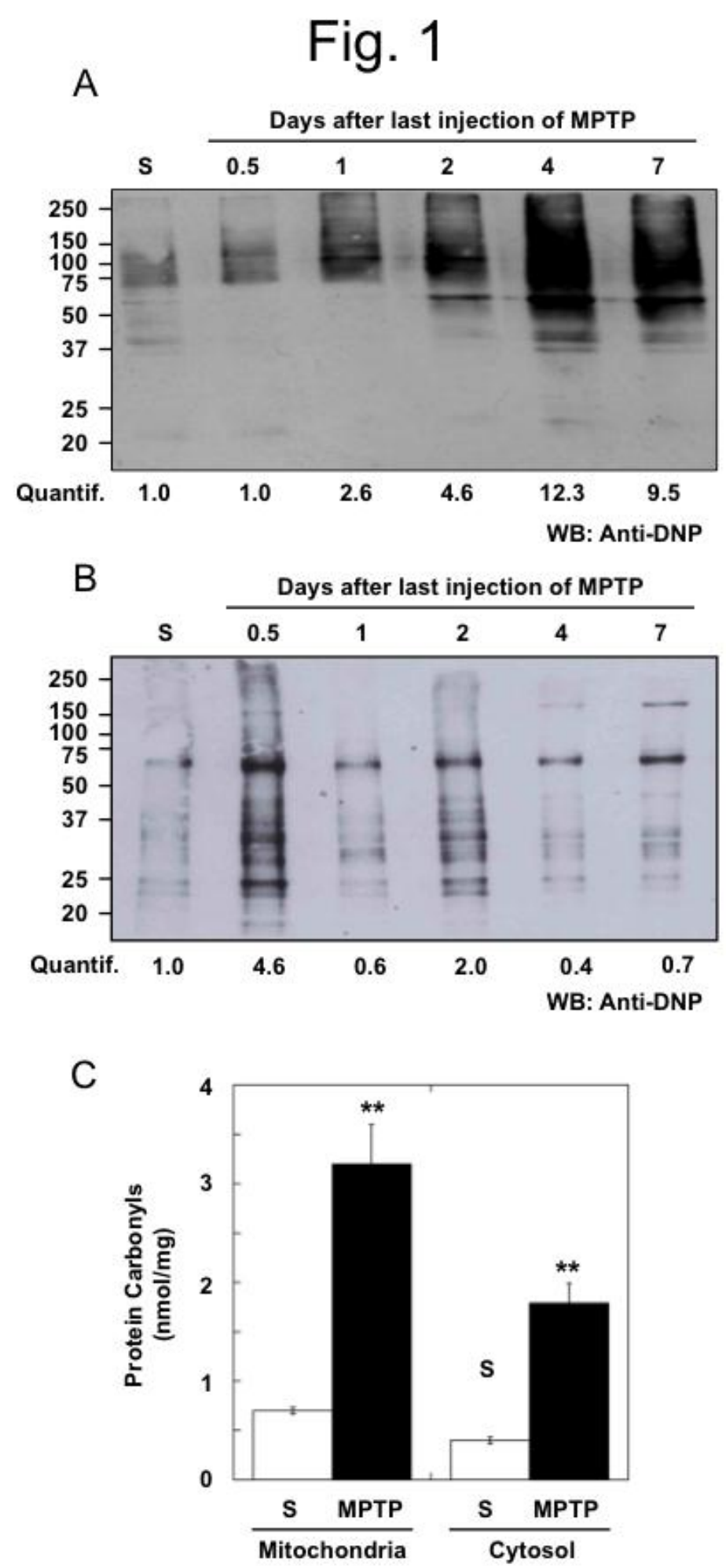
Fig. 2

A
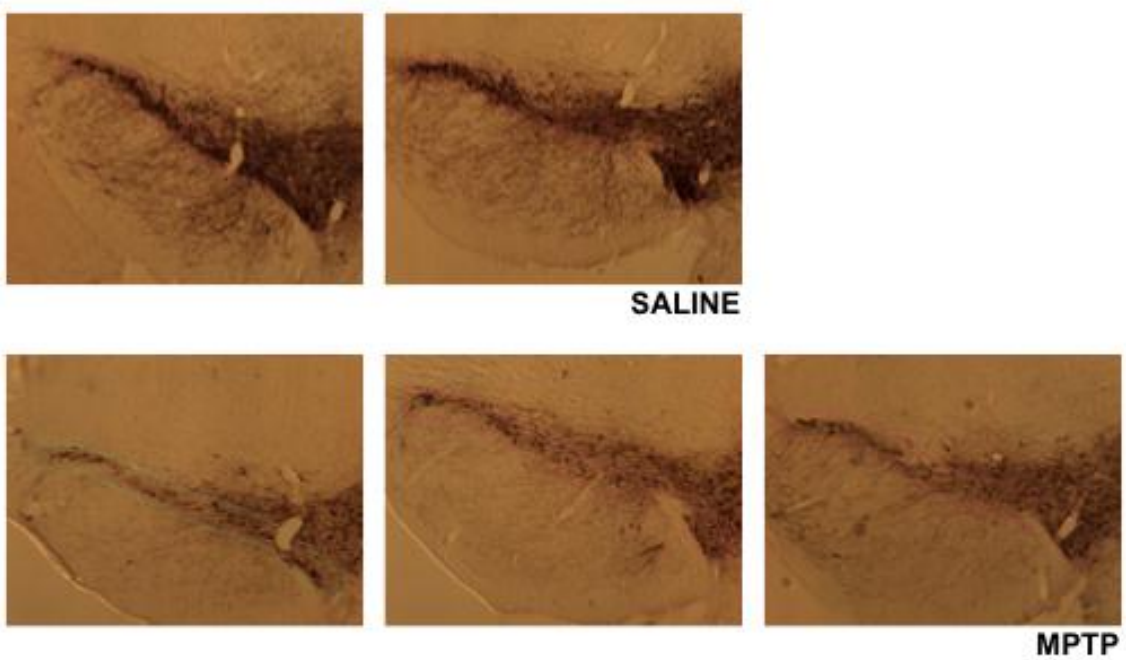

B

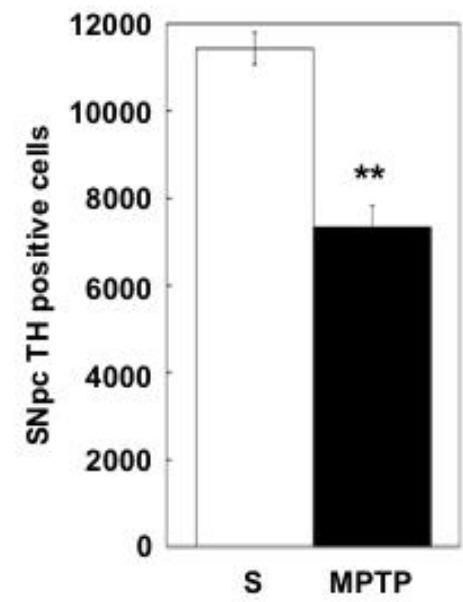

C

Days after last injection of MPTP

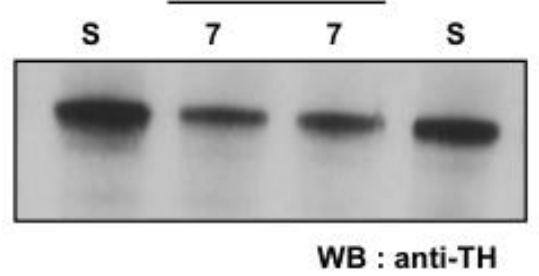

WB : anti-TH 
Fig. 3

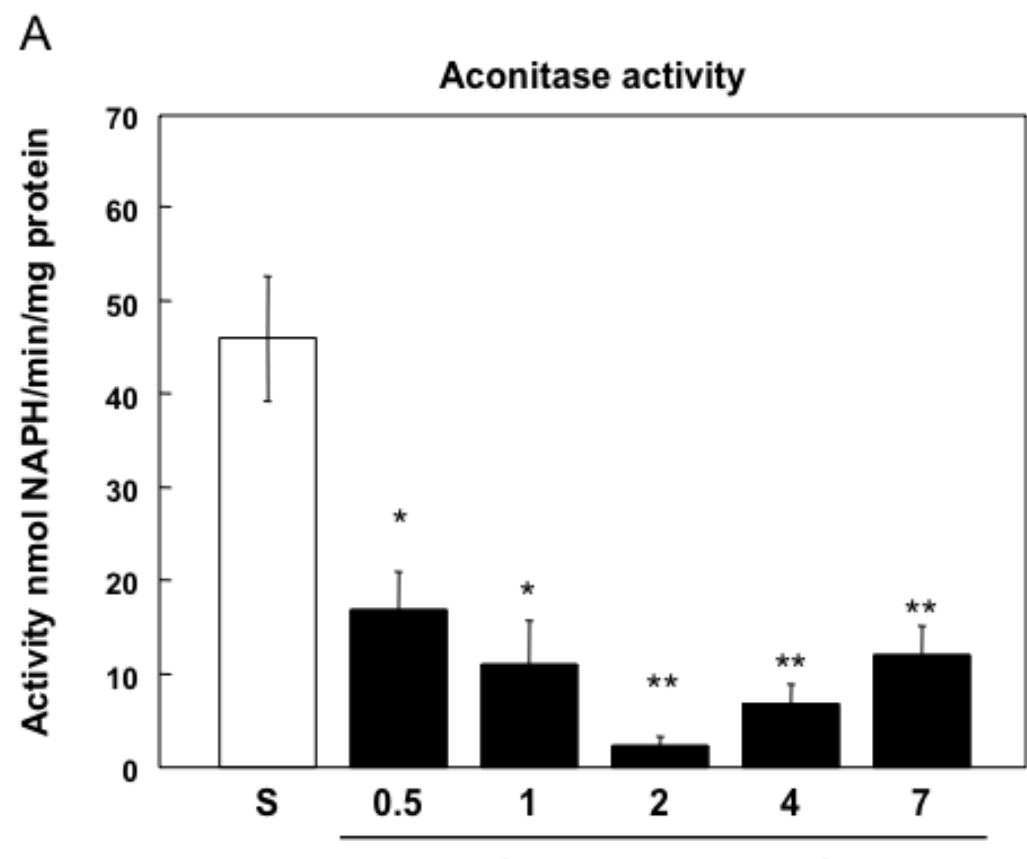

B

Days after last injection of MPTP

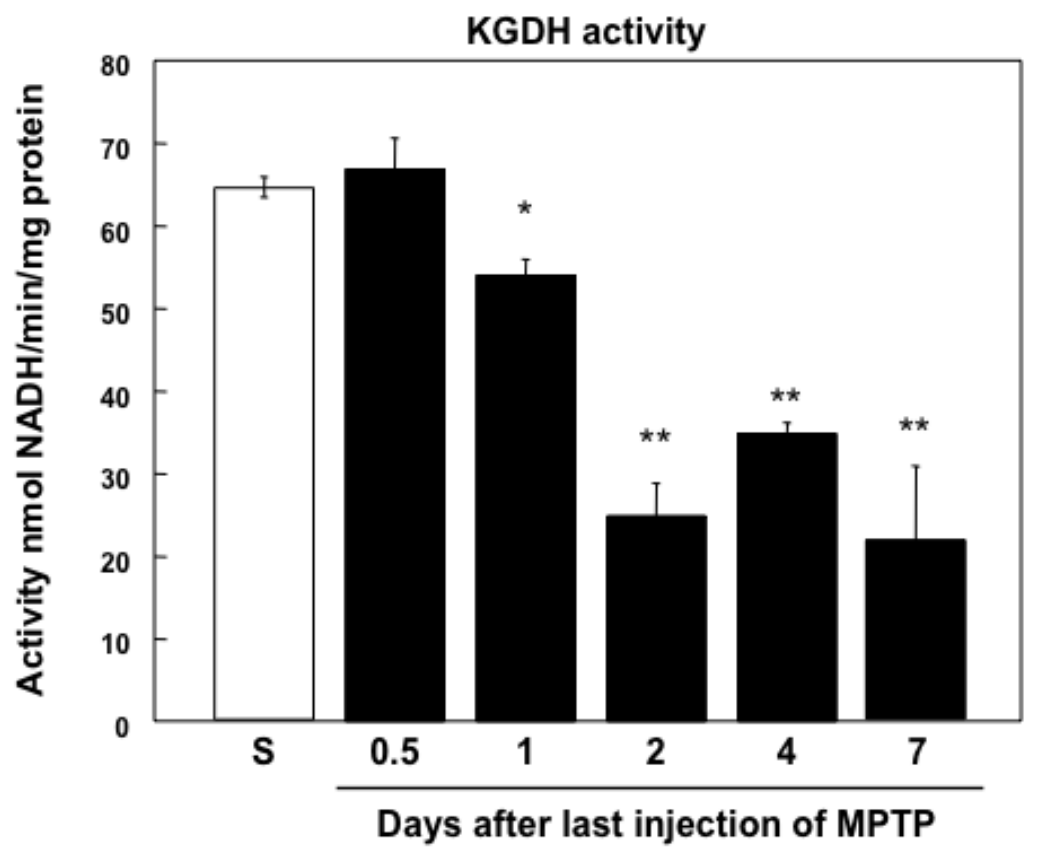


Fig. 4

A

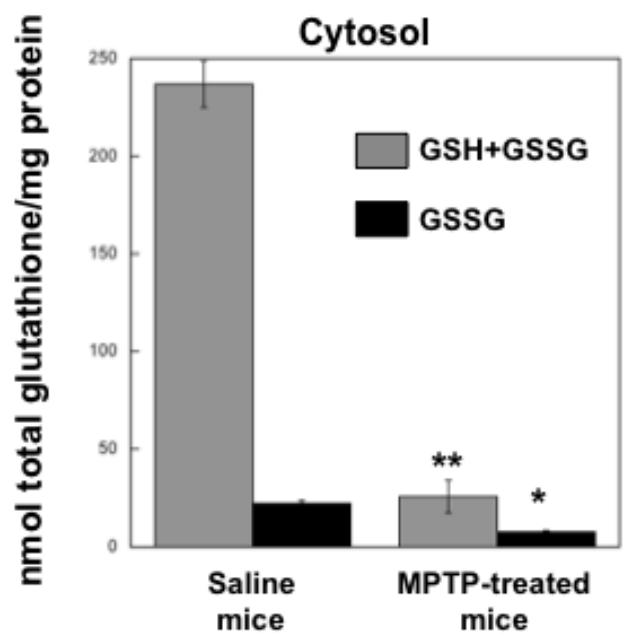

B

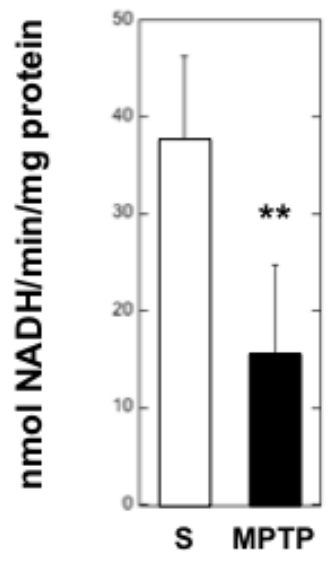

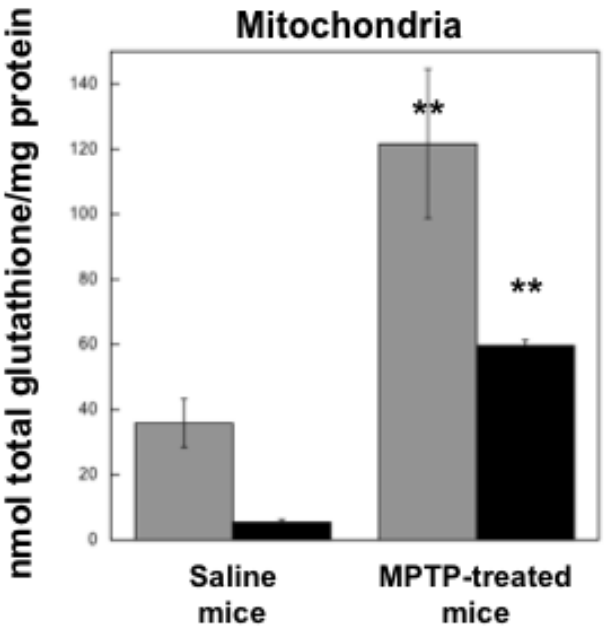

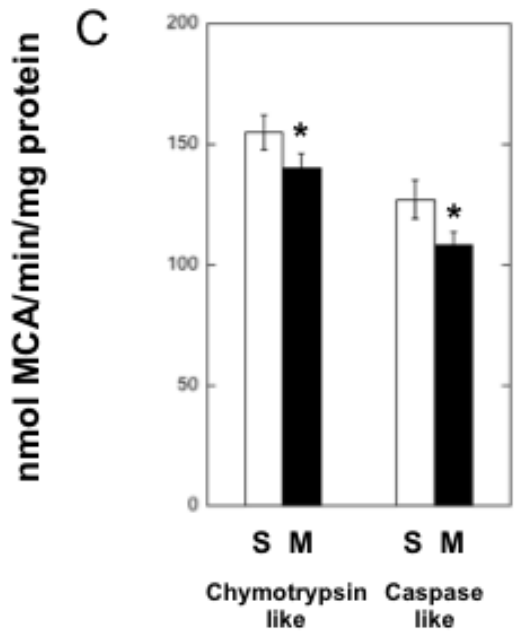


Fig. 5

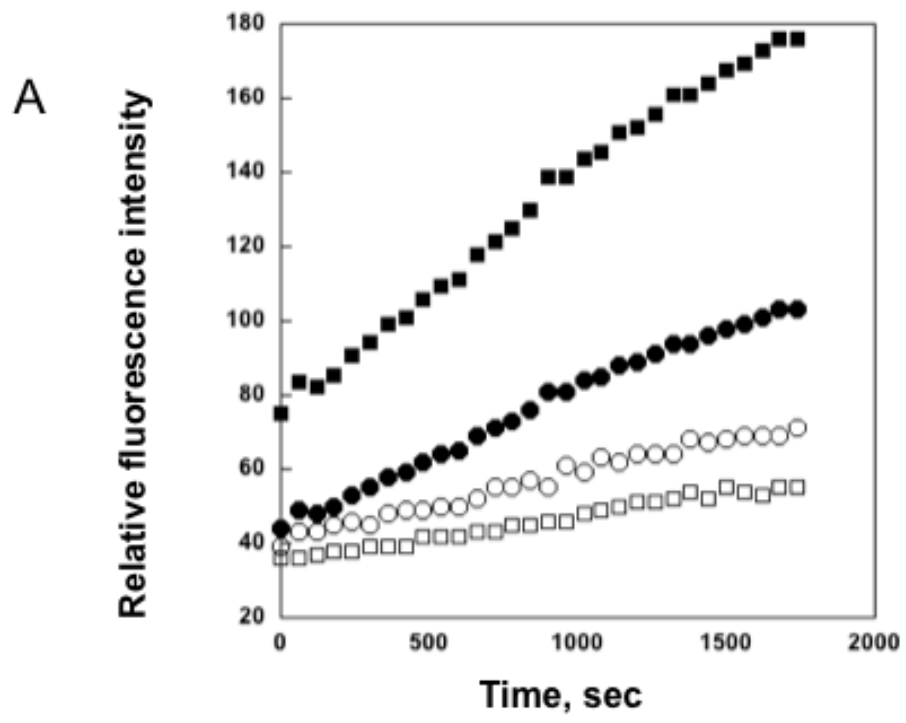

B

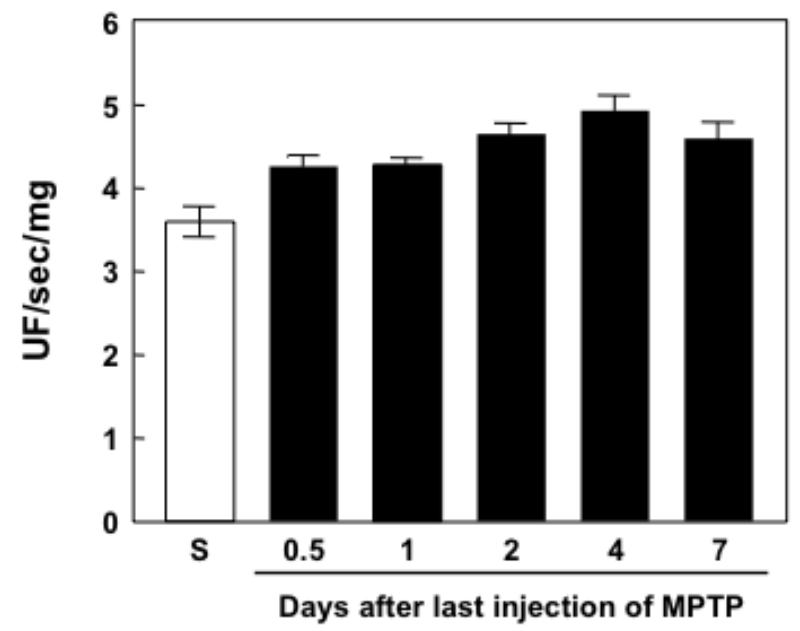

Days after last injection of MPTP

C

$\begin{array}{llllll}\mathrm{S} & 1 & 2 & 4 & 7\end{array}$

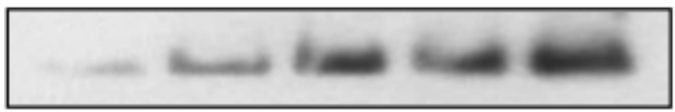

WB: anti-Lon

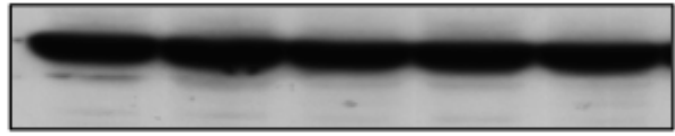

WB: anti-actin 
Fig. 6

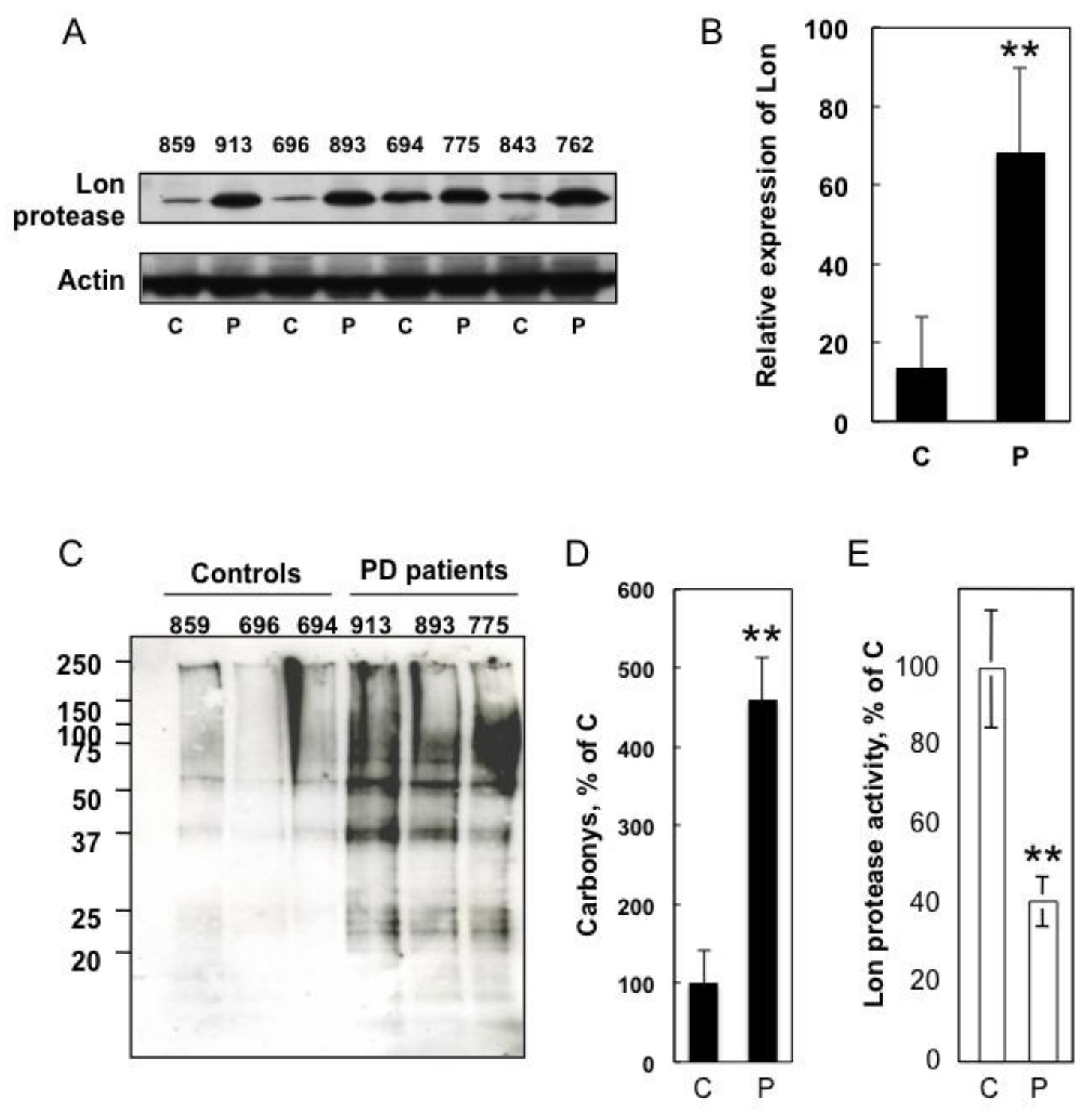


Fig. 7

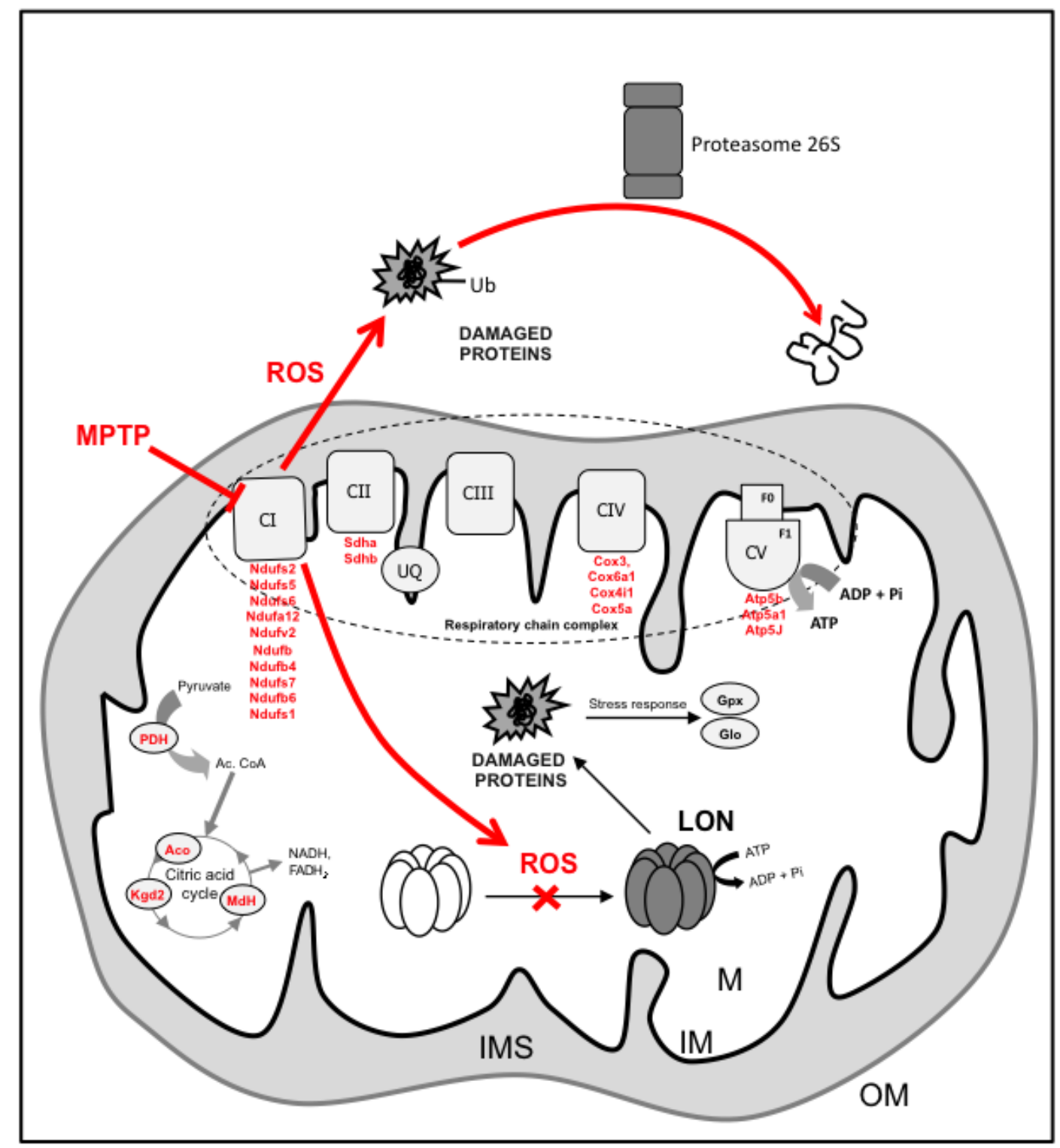

